\title{
Prohibitin ligands: a growing armamentarium to tackle cancers, osteoporosis, inflammatory, cardiac and neurological diseases
}

Dong Wang, ${ }^{1}$ Redouane Tabti, ${ }^{2}$ Sabria Elderwish, ${ }^{2}$ Hussein Abou-Hamdan, ${ }^{2}$ Amel Djehal, ${ }^{2,3}$ Peng Yu, ${ }^{1}$ Hajime Yurugi, ${ }^{4}$ Krishnaraj Rajalingam, ${ }^{4}$ Canan G. Nebigil, ${ }^{2}$ Laurent Désaubry ${ }^{1,2 *}$

1 Sino-French Joint Lab of Food Nutrition/Safety and Medicinal Chemistry, College of Biotechnology, Tianjin University of Science and Technology, Tianjin, China.

2 Laboratory of Cardio-Oncology and Medicinal Chemistry (FRE 2033), CNRS, Institut Le Bel, 4 rue Blaise Pascal, CS 90032, 67081 Strasbourg, France

${ }^{3}$ Superior National School Biotechnology Taoufik Khaznadar, Ville universitaire Ali Mendjeli, BP E66 25100, Constantine, Algeria

${ }^{4}$ Cell Biology Unit, University Medical Center Mainz, JGU-Mainz, Germany

*Correspondance: desaubry@unistra.fr, phone: 33-368-851-606

ORCID numbers: Dong Wang: 0000-0002-4855-0576; Peng Yu: 0000-0002-3011-3837; Krishnaraj Rajalingam: 0000-0002-4175-9633; Canan G. Nebigil: 0000-0002-2035-5795 ; Laurent Désaubry : 0000-0002-1192-2970.

\begin{abstract}
Over the last three decades, the scaffold proteins prohibitins-1 and -2 (PHB1/2) have emerged as key signaling proteins regulating a myriad of signaling pathways in health and diseases. Small molecules targeting PHBs display promising effects against cancers, osteoporosis, inflammatory, cardiac and neurodegenerative diseases. This review provides an updated overview of the various classes of PHB ligands, with an emphasis on their mechanism of action and therapeutic potential. We also describe how these ligands have been used to explore PHB signaling in different physiological and pathological settings.
\end{abstract}

\section{Keywords}

Cell signaling, scaffold proteins, MAP kinase, C-RAF, RAF1, KRAS, NF-kB, Wnt, LC3, mitophagy, cancer, drug discovery, inflammation, cardiac diseases, Alzheimer disease, Parkinson disease, autoimmune disease, osteoporosis, osteoclastogenesis, cardio-oncology, melanogenesis. 


\section{Regulation and functions of PHBs}

Prohibitins-1 and -2 (PHB1/2) are pleiotropic scaffold proteins involved in many important cell functions, including survival, proliferation, metabolism, and mitochondrial dynamics (Fig 1) [1-6]. This review will, in the first instance, provide a general overview how PHBs are regulated through many post-translational modifications and how they control a myriad of signaling pathways before to present every class of PHB ligands, with an emphasis on their pharmacological potential. The primary aim of this article is to collate and comprehensively analyze various studies employing PHB ligands which in turn shed further insights into the physiological and pathophysiological roles of prohibitins. Ultimately, it is not unlikely that these forays will stimulate further investigations to unravel the central role of PHBs in cell physiology and lead to important clinical applications.

PHBs can be phosphorylated at several different positions (Fig 2 and Table 1 ) by Akt, Cam kinase IV, Aurora A, protein kinase C (PKC), Lyn and the receptors to insulin [1,6]. PHBs are also regulated by $O$ GlcNAc modifications, $\mathrm{N}$-myristoylation, palmitoylations, tyrosine nitrosylation and sulfatation, transamidations and arginine deamination (Figs 1 and 2, Table 1). All of these regulations have two consequences. First, they modify the binding of PHBs to specific lipids, which orientate their localization to specific cellular compartments such as the plasma membrane, mitochondria, endoplasmic reticulum, peroxisomes, the cytosol and the nucleus [7]. Second, the conformational changes could dictate the interaction of PHBs with their partner proteins and thus the signaling events associated with them. Currently, the function of many of these post-translational modifications has not been explored. Yet, the interplay between the established phosphorylation, O-GICNAc modification and palmitoylation is complex and has been recently described in an excellent review [1]. How these events reflect on the structure of PHBs remain an open question as no 3D structure of full length PHB has been established yet. Only the coiled-coil region of PHB2 has been solved. This motif was shown to interact with a number of mitochondrial intermembrane space proteins [8].

In addition, PHBs also binds to second messengers: phosphatidylinositol 3,4,5-triphosphate (PIP3) for PHB1 to modulate the signaling of Tyr kinase receptors and also sphingosine-1-phosphate (S1P) for PHB2 to promote cytoprotection $[9,10]$. 


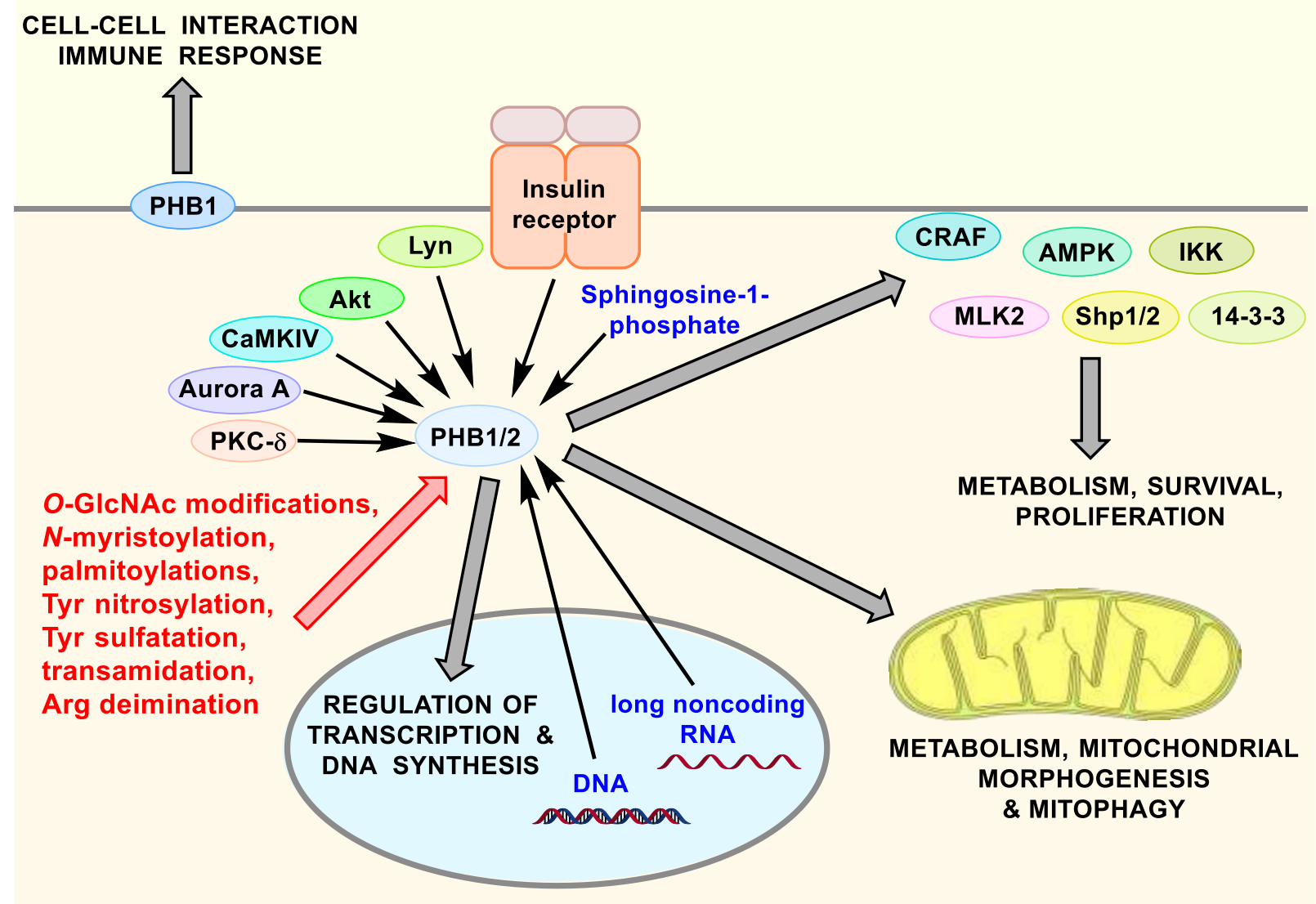

Fig. 1 Overview of PHB signaling. Post-translational modifications and endogenous ligands (sphingosine1-phosphate, DNA and long noncoding RNA) regulate the intracellular localization of PHBs along with their interactions with signaling proteins such as the kinases AMPK, C-RAF, IKK, MLK2, the phosphatases Shp 1/2 or the scaffold protein 14-3-3. 

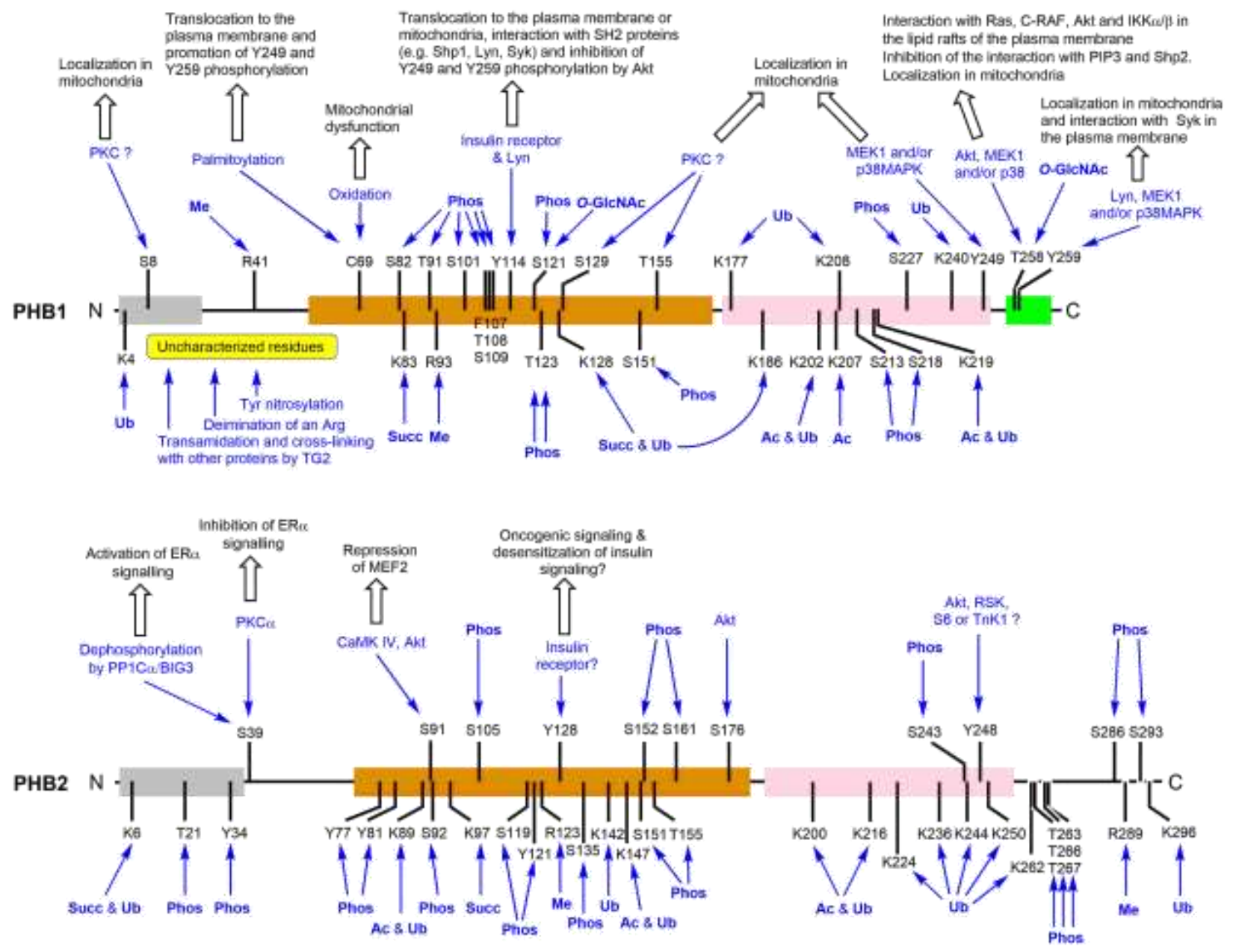

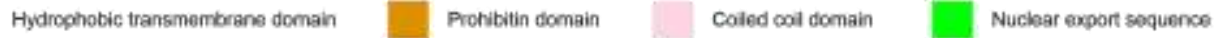

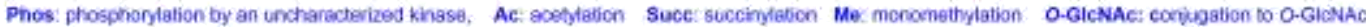

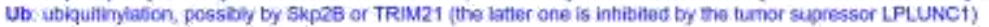

Fig. 2 Schematic representation of PHB1 and PHB2 showing the location of known post-translational modification sites [11].

In the cytosol and the inner face of the plasma membrane PHBs interact with a multitude of signaling proteins, such as the kinases C-RAF (RAF1), Akt, IKK, MLK2, the phosphatase Shp1/2, the scaffold proteins 14-3-3 and the cytoskeleton protein $\alpha$-actinin to cite few representative examples.

One of the determinant factors of PHB functions is their localization within cells. On the outer face of the plasma membrane, PHBs are involved in cell-cell interactions [12], the immune response $[13,14]$ and also to the chemoresistance to taxoids in cancer cells [15]. In the nucleus, PHBs interact with several transcription factors (p53, NRF2, estrogen receptor, androgen receptor, E2Fs, HES1, MyoD, CTCF, MEF2, MAFG, c-MYC and MAX [16-27]), transcriptional co-activators and co-repressors to regulate transcription, methionine adenosyltransferase $\alpha 1$ (MAT 1 ) [26] and also to the minichromosome maintenance protein complex that controls DNA replication [28]. For example, PHB1 heterodimerizes with MAX and MAT $\alpha 1$ to bind to the E-box element and repress its promoter activity [26]. PHBs also trap 
the transcription factors HES1 and STAT3 outside the nucleus to inhibit their transcriptional activity $[29,30]$. In the case of STAT3, this interaction takes place in mitochondria to promote cell survival [29,31].

In addition, PHBs can also bind to DNA and RNA. Indeed, both PHB1 and PHB2 directly bind to the (TGYCC) ${ }_{15}$ motif of the promoter of p53-induced gene 3 (PIG3) to enrich the PIG3 transcription, thereby provoking apoptosis [32]. PHB1 also binds with a high affinity to mitochondrial DNA [7]. PHB2 itself interacts with the long non-coding RNA LOC283070 in the nucleus to inhibit the activity of the androgen receptor in prostate cancer cells [33]. In the inner membrane of mitochondria, alternating PHB1 and PHB2 assemble into ring complexes to regulate metabolism, mitochondrial fusion, morphogenesis, mitophagy, survival, apoptosis and cell proliferation [34]. All these interactions could be governed by posttranslational modifications in a context and cell type dependent manner.

\section{PHBs ligands}

Several classes of PHB ligands have been discovered. Importantly, these different classes of compounds display diverse profiles of pharmacological activities, suggesting that they stabilize different conformations of PHBs. The most studied class of PHB ligands are natural compounds called flavaglines found in trees used in traditional Chinese medicine. Most of the other types of PHBs ligands are synthetic small molecules identified in phenotypic screenings.

Considering that genetic inactivation or deletion of PHBs induce cellular dysfunction due to their essential role in mitochondria, PHB ligands represent invaluable tools to unravel their role in physiology in addition to their therapeutic potential.

\section{Flavaglines}

\section{Structure and identification of their targets}

Flavaglines were first discovered in 1982 based on their antileukemic effects [35]. Their structure is characterized by a complex cyclopenta[b]benzofuran (Fig. 3), which has been the object of many total syntheses (recently reviewed in [36]). Their most striking feature is their unique ability to induce death pathways in the cancer cells, while they promote survival pathways in non-cancer cells such as neurons and cardiomyocytes toward various types of stresses. 

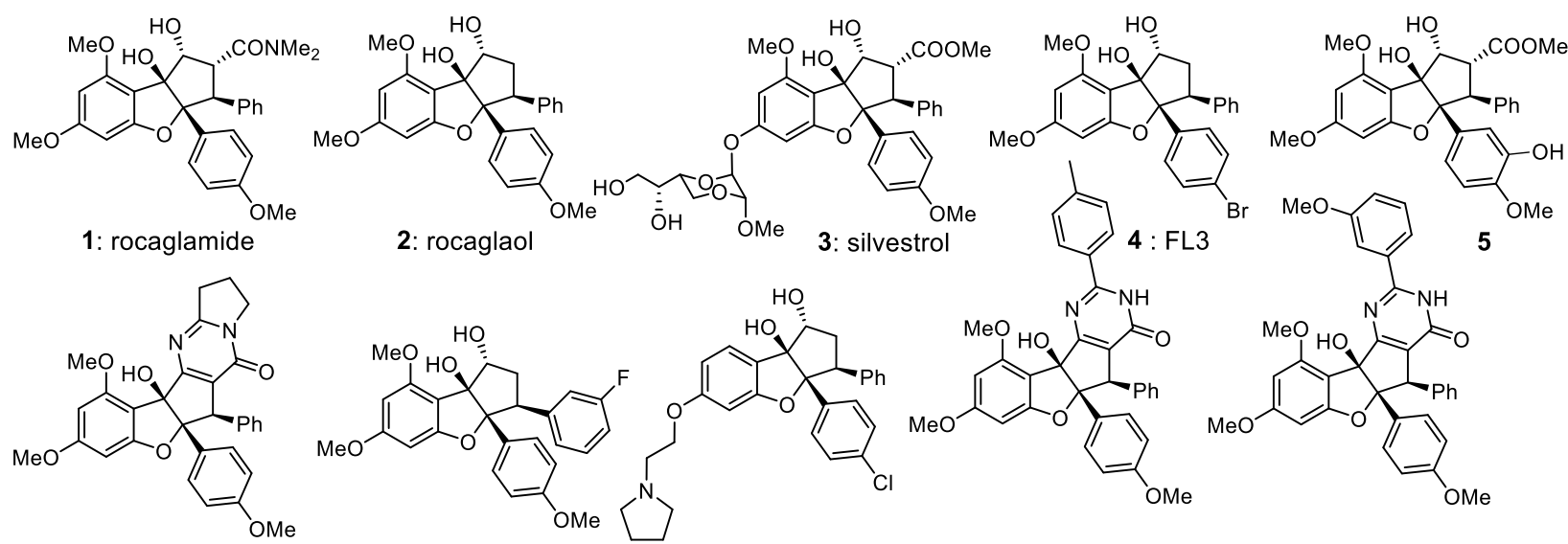

2: rocaglaol
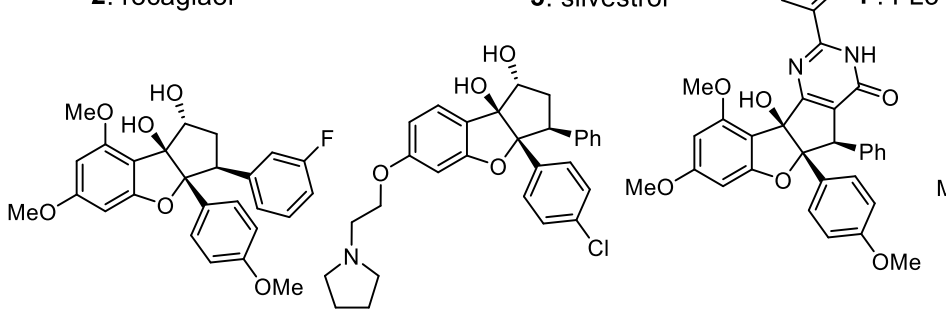

6: aglaroxin $\mathrm{C}$

$7:$ IMD-019064

8 : IMD-026259

9: CMLD012043

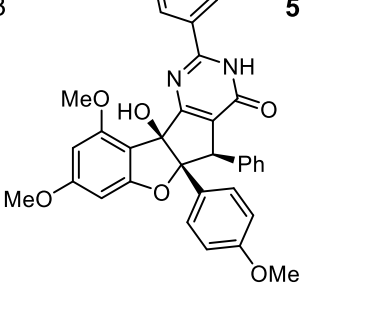

10: CMLD012044

Fig. 3 Representative examples of pharmacologically active natural and synthetic flavaglines.

The pharmacology of flavaglines is complex (Fig. 4). In addition to their effect on PHB signaling, flavaglines also inhibit the initiation factor of translation elF4A. elF4A is necessary for the translation of a small fraction of mRNAs that mainly code for proteins involved in cancer signaling. While the inhibition of elF4A is critical for every cancer cell type, the action on PHB is cell type dependent. Indeed, every cancer cell seems to display a high activity of elF4A to drive a translational program supporting tumorigenesis. Thus, a partial inhibition of elF4A can be sufficient to kill cancer cells without being toxic to normal cells [37]. On the opposite, the role of PHBs in cancer varies widely according to the cell type. Some tumors overexpress PHBs, but not all of them [38]. In addition, this overexpression can be manifested in the nucleus or in mitochondria depending of the cell type. It is thus clear that the signaling and function of PHBs differ according to the type of cancer cells.

In this review, we focus on the pharmacological effects that have been demonstrated to be mediated by a modulation of PHB signaling. Early investigations in 80's and the 90's showed that flavaglines postpone tumor growth, but do not eradicate the tumors. These observations put a halt to further studies, until LiWeber and collaborators identified by affinity chromatography PHB1 and PHB2 as bona fide targets of flavaglines [39].

\section{Inhibition of Ras/C-RAF/MEK/ERK signaling}

Importantly they showed that these compounds block the activation of C-RAF (Raf-1) by Ras. Indeed, the binding of growth factors to tyrosine kinase receptors triggers a cascade of events that induces the Ras/C-RAF/MEK/ERK signaling pathway to promote cancer development. The activation of the protein kinase C-RAF by the proto-oncogene RAS requires a direct interaction of PHBs with C-RAF that is blocked by flavaglines $[39,40]$. Inhibition of C-RAF/MEK/ERK signaling was shown to be determinant to the in vivo antitumor effect of flavaglines in murine models of ERK-driven pancreatic ductal adenocarcinoma [41], vemurafenib resistant melanoma [42], KRAS-mediated lung [43], and neuroblastoma [44]. 
Recently, flavaglines have been shown to inhibit also the activation of KRAS [43]. This isoform of RAS is one of the most frequently mutated oncogenes in human cancers. More specifically, flavaglines inhibit KRAS-GTP loading in KRAS-mutated cells as well as in EGF-stimulated cells. Considering that after 3 decades of intensive research no inhibitor of KRAS has yet been approved for the treatment cancers, this appealing effect of flavaglines is poised to be further explored.

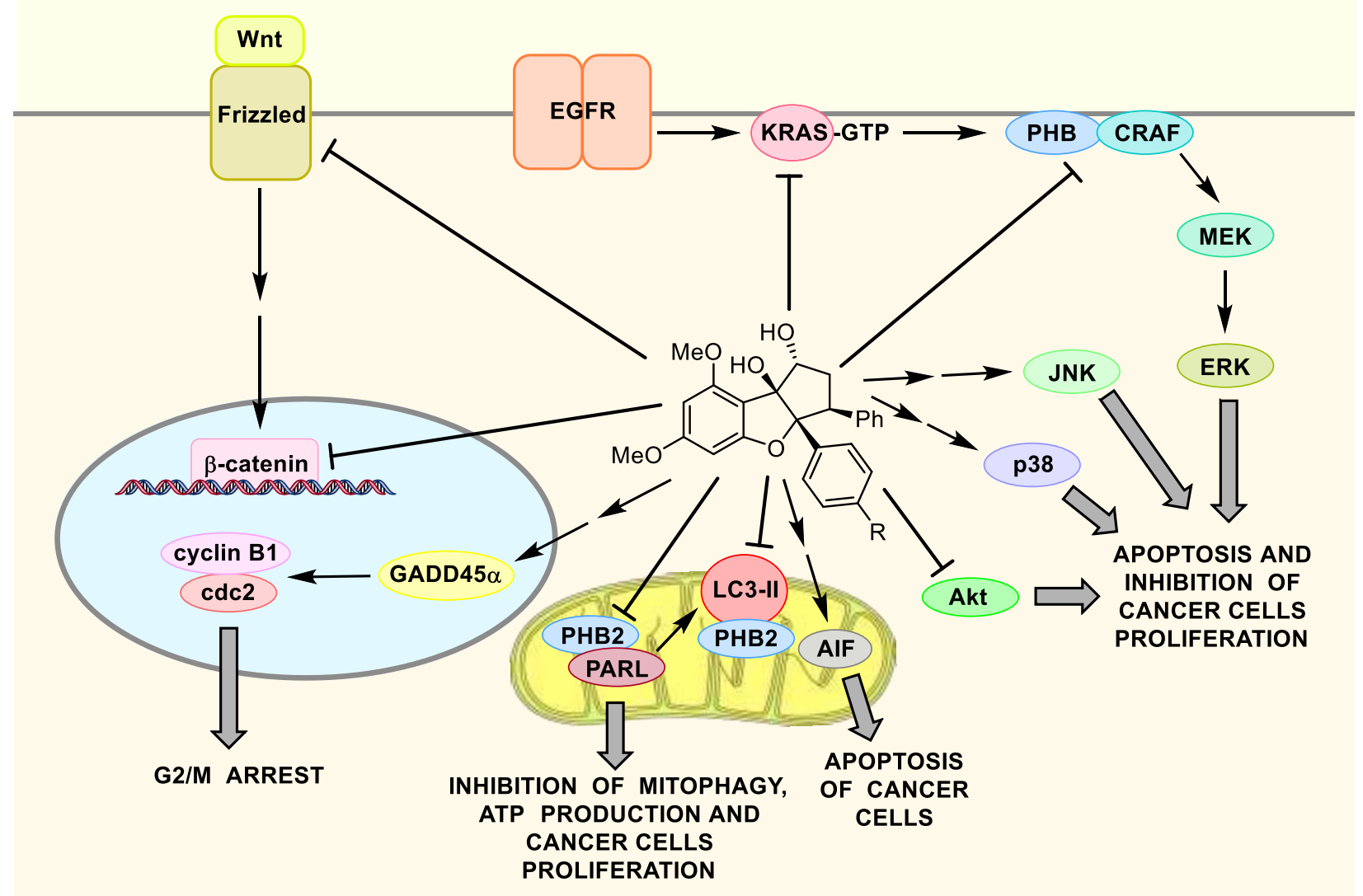

Fig. 4 Overview of the mechanism of action of flavaglines in cancer cells involving PHBs. Flavaglines inhibit the activation of KRAS and C-RAF, to block the C-RAF/MEK/ERK pathway necessary to the survival of many cancer cell types. In bladder cancer, flavaglines inhibit PHB1 phosphorylation by Akt, leading to removal of PHB1 in mitochondria. Flavagline also upregulate GADD45 $\alpha$ to inhibit cdc2/cyclin B1 kinases and cell cycle progression in the G2/M phase. They can also inhibit the signaling of the paracrine factor Wnt that is necessary to the survival of several cancer cell types. Moreover, flavaglines block mitophagy and energy productions by inhibiting the effects of PHB2 on the mitochondrial inner protease PARL and LC3-II. Flavaglines can also induce apoptosis of cancer cells by activating AIF, JNK, p38 through yet uncharacterized mechanisms. Although it is critical to the cytotoxicity of flavaglines in cancer cells, the action of flavaglines on the initiation factor elF4A is not disclosed to remain in the scope of this review.

Many studies have demonstrated that flavaglines exhibit potent anticancer properties in mouse models of human cancers, but whether these effects are due to on action on elF4A or PHBs remains uncertain in vivo. Nevertheless, rocaglamide (1) has been shown to reverse C-RAF-mediated vemurafenib resistance 
in a human melanoma xenograft model due to its effect on PHBs leading to an inhibition of C-RAF [45]. Another flavagline, FL3 (4) also prevents the oncogenic growth in mouse models of bladder and KRASdriven non-small cell lung cancer through its effects on PHBs $[46,43]$. Importantly, PHB1 was overexpressed in both types of cancer. Inhibition of KRAS/C-RAF signaling was proposed to be determinant for the apoptosis of non-small cell lung tumors [43].

\section{Activation of GADD45 $\alpha$ signaling}

For the urothelial carcinoma of the bladder, another mechanism was proposed: binding of FL3 to PHB1 inhibits its phosphorylation by Akt, which consequently decreases the localization of PHB1 in the mitochondria [46]. Besides, microarray analysis of mRNA expression experiments indicated that both FL3 treatment and PHB1 knockdown upregulate the mRNA expression of the growth arrest and DNA damage-inducible alpha (GADD45 $\alpha$ ) gene that inhibits $C d c 2$ kinase to promote $G_{2} / M$ arrest. Additionally, knocking down the expression of GADD45 $\alpha$ blocked the inhibitory effect of FL3 on cell cycle, indicating that GADD45 $\alpha$ upregulation is critical to FL3-induced cell cycle inhibition.

\section{Inhibition of NF-kB signaling}

Flavaglines also inhibit the signaling of Nuclear Factor KB (NF-KB), which is a transcription factor that regulates the immune responses, inflammation, differentiation, and cell survival. NF-KB family members (p50, p52, p65 (RelA), RelB, and c-Rel) form various homo- or heterodimers. In unstimulated cells, these NF-kB dimers are sequestered in the cytoplasm by the inhibitory family protein IkB. Upon activation by several receptors, the IKK complex IKK $\alpha /$ IKK $\beta /$ NEMO phosphorylates IKB to induce its degradation (Fig. $5)$. This event releases NF-KB dimers and allows them to translocate into the nucleus to regulate transcription. Recently, Liang and coll. showed that phosphorylation of PHB1 at T258 promote its association with MEKK1, IKK1 and IKK2 in the membrane raft of lung cancer cells to promote NF-KB signaling and consequently to enhance metastasis [47]. In contrast, Lu and coll. found that silencing PHB1 activates NF-KB signaling in liver cancer cells to stimulate tumorigenesis by enhancing the expression of interleukin 8 [48]. Interestingly, flavaglines had been shown to inhibit canonical NF-KB pathway in Jurkat T cells at nanomolar concentration [49]. This report was done prior to the discovery of PHBs as the target of flavaglines [39], and consequently the relationship with PHBs was not explored. However, the authors found that flavaglines act upstream of the IkB kinase complex and downstream of the TNF receptor-associated protein 2, which is coherent with an action on PHBs. More recently, rocaglamide was shown to inhibit the phosphorylation of NF-KB component p65 protein and its localization in nucleus [50]. This inhibition of NF-KB signaling promoted osteoblast differentiation, suggesting that flavaglines hold some potential to prevent the bone loss associated to rheumatoid arthritis. Whether flavaglines disrupt the interaction between PHB1 and the kinases MEKK1, IKK1 or IKK2 and the functional consequences thereof have not been examined yet. 


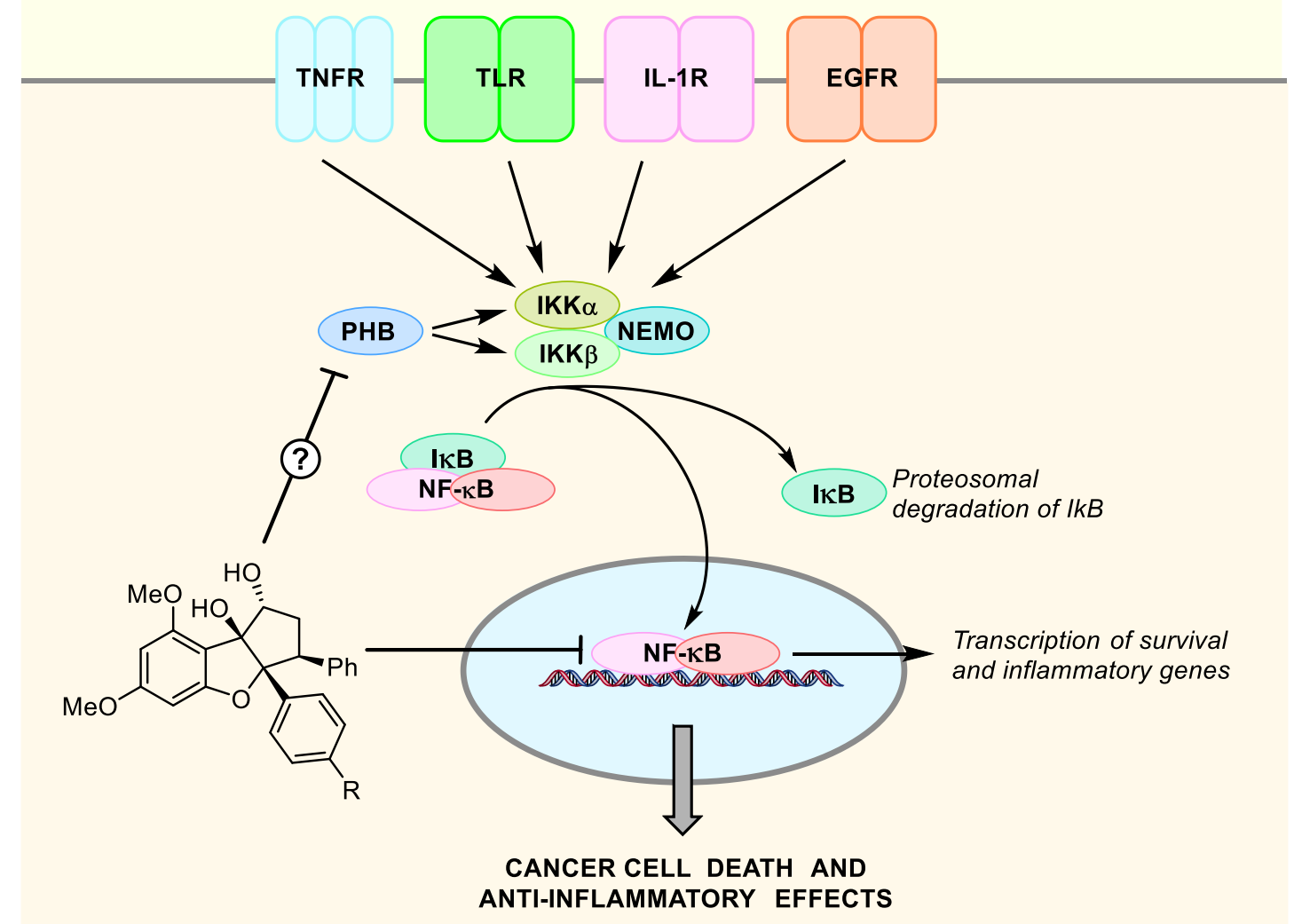

Fig. 5 Inhibition of NF-KB signaling by flavaglines.

Rocaglamide (1) has also been shown to prevent metastasis of cancer cells by inhibiting the formation of pseudopodia, which are extension of the cytoplasm enriched in PHBs used by cancer cells to migrate [51].

\section{Inhibition of Wnt signaling}

In addition to these mechanisms, flavaglines inhibits Wnt signaling in STF/293 cells [52]. Wnt is a paracrine glycoprotein that activates a Frizzled receptor at the cell surface to block the degradation of the transcription factor $\beta$-catenin. Recently, PHB1 was shown to repress the expression of several Wnt ligands and inhibit canonical Wnt signaling [53]. Several flavaglines have been tested for their effect on Wnt signalling, and compound 5 displayed the highest anti-Wnt activity $\left(\mathrm{IC}_{50}\right.$ of $\left.32 \mathrm{nM}\right)$ and also the highest cytotoxicity in TRAIL-resistant cancer cells [52].

\section{Inhibition of mitophagy}

Moreover, flavaglines inhibit mitophagy and energy production in cancer cells (Fig. 6). Indeed, PHB2 is involved in mitophagy, which is the selective removal of damaged or unwanted mitochondria. In normal condition, the mitochondrial kinase PINK1 and the phosphatase PGAM5 are continuously processed and degraded by mitochondrial inner proteases PARL and m-AAA, i-AAA. Upon mitochondria depolarization 
or damage, PHB2 directly inhibits PARL to prevent the degradation of PGAM5 and PINK1. Then, PINK1 can migrate to the outer mitochondrial membrane (OMM) to recruit the cytosolic E3 ubiquitin protein ligase Parkin to the OMM where it induces the ubiquitination and degradation of OMM proteins, resulting in OMM rupture, which allows PHB2 to interact with LC3-II in phagophores and initiate mitophagy.
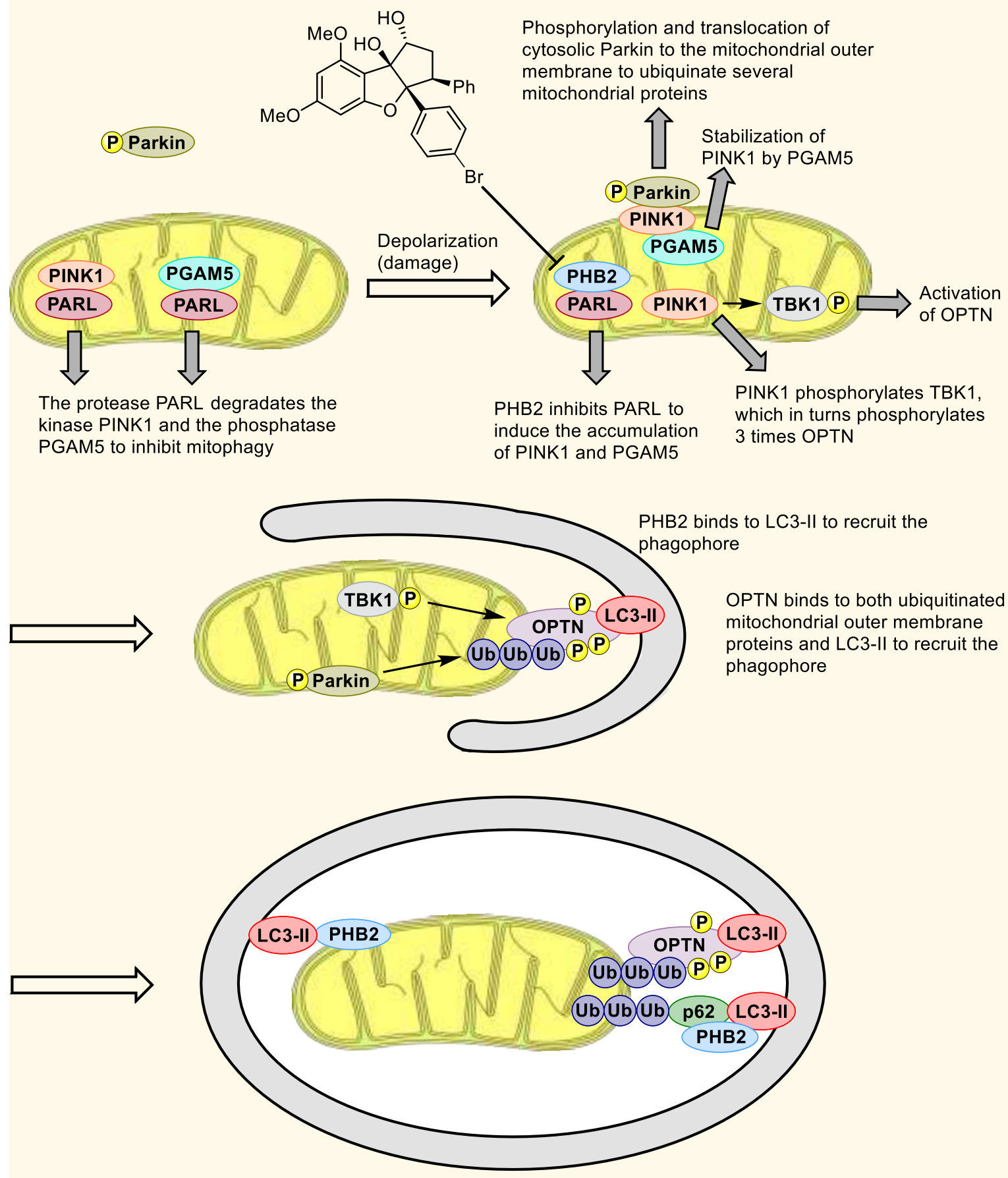
Fig. 6 Regulation of mitophagy by PHB2. In healthy mitochondria the protease PINK1 and the phosphatase PGAM5 are continuously imported and degraded by the protease PARL. Upon damage, PHB2 interacts with PARL to block its activity leading to accumulation of uncleaved PINK1 on the outer mitochondrial membrane. Then PINK1 phosphorylates the ubiquitinated chains conjugated to mitochondrial proteins as well as cytosolic Parkin and the kinase TBK1 to induce their activation. TBK1 phosphorylates 3 times Optineurin (Optn). Autophagy receptors, PHB2, Optn, and p62 interact with LC3II to recruit the phagophore and promote its expansion. Flavaglines inhibit the interaction between PHB2 and PARL, leading to an inhibition of mitophagy [54]. At the mitochondrial inner membrane, PHB2 forms ring-like oligomers with PHB1, but a role of PHB1 in mitophagy has not been established yet.

Two flavaglines, rocaglamide (1) and FL3 (4), have been found to inhibit the interactions between PARL and PHBs, the downregulation of PARL, PINK1 accumulation in depolarized mitochondria, the mitochondrial recruitment of Parkin and the elimination of mitochondria. Flavaglines not only inhibit PINK1/Parkin-mediated mitophagy, they also block energy production at nanomolar concentrations in cancer cells contributing to the anticancer activity of this class of PHB ligands.

\section{Antiviral activities}

Inhibition of C-RAF signaling holds some potential to treat not only cancers, bus also chronic hepatitis C virus (HCV) infection [55]. Indeed, PHBs interact with HCV at the plasma membrane to mediate HCV entry in a C-RAF dependent manner. These events are inhibited by several flavaglines, and in particular aglaroxin C (6), which displays a potency and therapeutic index superior to that of rocaglamide (1) and other flavaglines. Optimization of aglaroxin C led to the development of CMLD012043 (9) and CMLD012044 (10), which show an enhanced inhibition of HCV infection with low cytotoxicity [56]. These two compounds inhibit HCV viral entry into cells, but not HCV RNA replication and mRNA translation, suggesting that these effects are mediated by an action on PHBs rather than elF4A.

PHBs are also required to internalize Chikungunya virus into microglial cells. This internalization is partially blocked by flavaglines, but not sufficiently enough to have a genuine therapeutic potential [57]. Very recently, the enterovirus 71 (EV71), which causes Hand, Foot and Mouth Disease and also neurological complications in children has been shown to use cell surface-expressed PHB1 to facilitate its entry into the host cells [58]. Importantly, rocaglamide (1) is able to prolong the life EV71-infected mice and lower virus loads in their central nervous system. Mechanistic studies showed that this antiviral effect is not due to an inhibition of the C-RAF/MEK/ERK signaling, but to a diminution of the localization of PHB1 in mitochondria, which impairs viral replication.

\section{Cytoprotectant activities}

Not only flavaglines do not display overt signs of toxicity in vivo, but they protect the heart against the severe toxicity of anthracyclines, such as doxorubicin (Fig. 7). This class of chemotherapeutic agents is extremely used in spite of it severe cardiac adverse effects [59]. In a mouse model of acute toxicity to doxorubicin, the flavagline FL3 has been shown to increase the survival rate from 31 to $55 \%$ in 
doxorubucin treated mice [60]. This cardioprotective effect is mediated by activation of mitochondrial STAT3 and the small heat shock protein Hsp27 [60,31]. Signal transducer and activator of transcription 3 (STAT3) acts as a transcription factor in the nucleus and promotes survival when located in mitochondria. FL3 has been found to induce a phosphorylation of STAT3 and a translocation of both PHB1 and phosphorylated STAT3 into mitochondria to promote cell survival (Fig. 7) [31]. FL3 also activates Hsp27 to protect cells against many types of damage, including the cardiotoxicity of doxorubicin, through its chaperone activity, control of redox homeostasis, and inhibition of apoptosis [60]. Besides, FL3 induces the overexpression of PHB1 in cardiomyocytes, which reinforces their resistance to many types of insults. Interestingly, this compound has an opposite effect in bladder cancer cells where it down-regulates PHB1 expression [46].
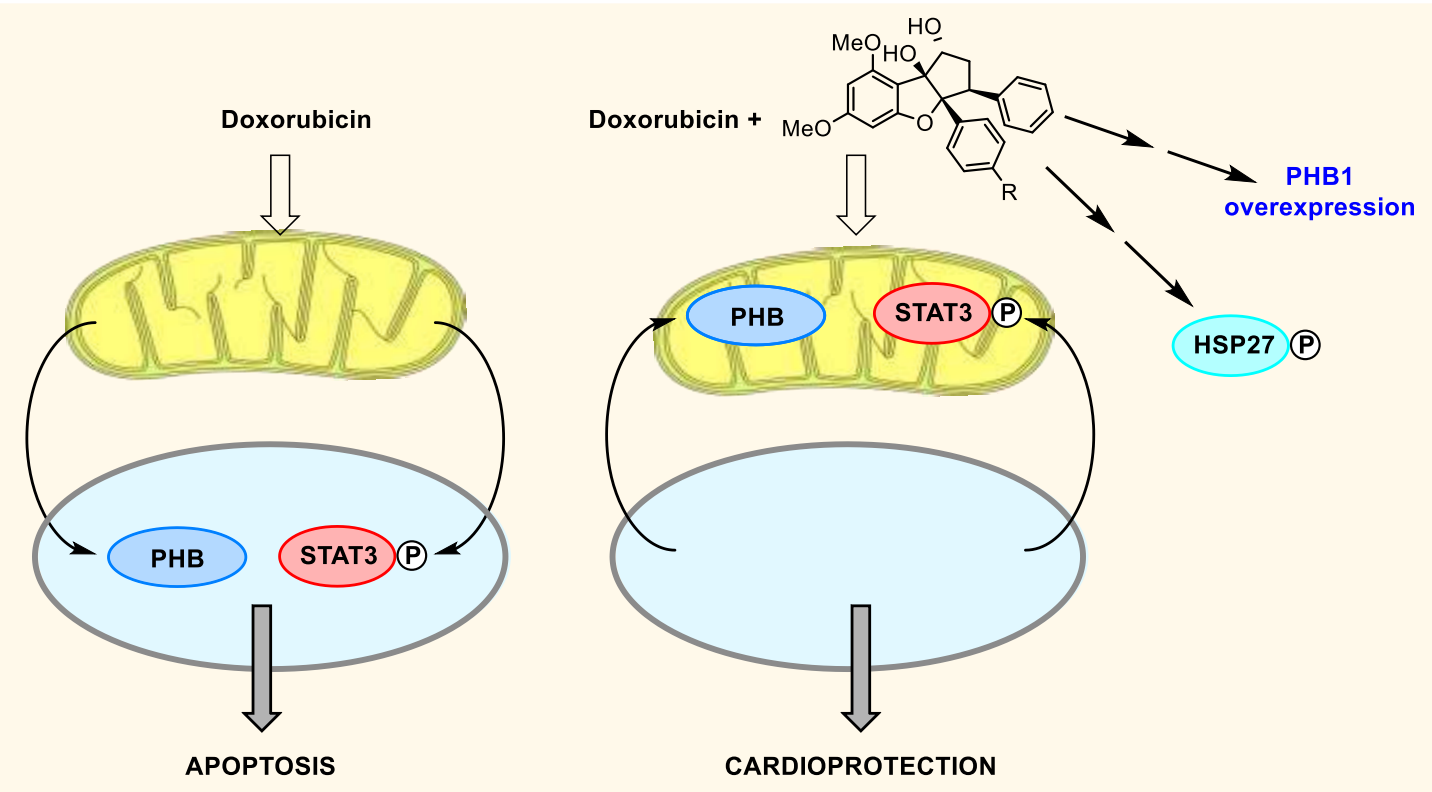

Fig. 7 Summary of the mechanism of cardioprotection against doxorubicin-induced cardiotoxicity. Doxorubicin is an anticancer drug that induces the apoptosis in cardiomyocytes and the translocation of PHB1 and STAT3 to the nucleus. Flavaglines protect cardiomyocytes by inducing the translocation of PHB1 and STAT3 to mitochondria, a phosphorylation of Hsp27 and an overexpression of PHB1.

Recently, FL3 was shown to promote the survival of non-cancer normal skin cells through the phosphorylation of the anti-apoptotic protein Bad by Akt, which unraveled a new mechanism of resistance to cell death by flavaglines (Fig. 8) [61]. 


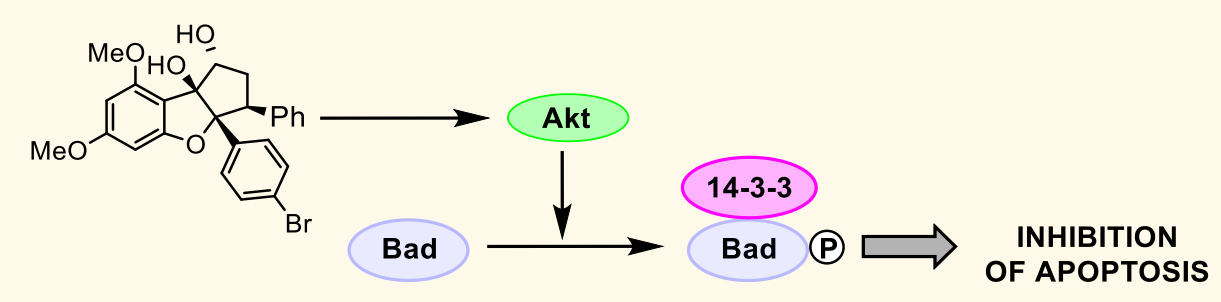

Fig. 8 Pro-survival activation of Bad by flavaglines in non-cancer cells.

Interestingly, the structural requirements for cardioprotection and the anticancer effects are quite similar. In a series of analogues, the relative order of activity may change, but all cardioprotectant flavaglines display are also cytotoxic in cancer cells and vice versa [62].

Similarly, another synthetic flavagline, IMD-019064 (7), developed by Bayer scientists has also been shown to display anti-inflammatory and neuroprotectant properties in mouse models of Parkinson and traumatic brain injury [63]. Further optimization of this compound has yielded to IMD-026259 (8), which has been developed for the treatment of Parkinson's disease.

In line with these observations, Li-Weber and coll. have found that rocaglamide (1) protects normal T cells against chemotherapeutic agents targeting DNA such as doxorubicin, teniposide, and bleomycin [64]. Rocaglamide has been shown to protect normal human peripheral blood B cells, NK cells, neutrophils, cardiomyocytes, hematopoietic stem cells and progenitor cells (HSPCs) against the cytotoxicity of etoposide. These data indicate that flavaglines can protect a wide array of primary nonmalignant cells from DNA damage-induced cytotoxicity. Overall, these data support the model that flavaglines could protect cancer patients against the adverse effects of chemotherapies.

Flavaglines are also able to protect mice in a model of Crohn's disease in which inflammation is driven by epithelial ulceration of the colon [65]. In this model, FL3 (4) decreased the inflammation of the colon and in the same time promoted the survival of the intestinal epithelial cells against the inflammatory stress. Importantly, in accordance with the findings on the context of cytoprotection in cardiomyocytes [31], FL3 also increased the expression of PHB1 in intestinal epithelial cells. This observation is important, because cells tend to overexpress PHB1 to protect themselves against various kinds of stresses. In addition, Theiss and coll. showed that PHB1 is down-regulated during intestinal inflammation and overexpressing PHB1 in mice alleviates the inflammatory damages of the colon in an in vivo model of Crohn's disease [66].

\section{Pharmacological development}

Despite the demonstrated efficacy of flavaglines in preclinical models of cancers, inflammatory, neurological and cardiac diseases, these compounds have not entered in a clinical trial yet. The major obstacle toward this end is an intellectual property issue. Indeed, flavaglines have been first examined two decades ago when their molecular targets were unknown. At that time, drug discovery was conducted differently. Now, we have a more useful scientific background to develop these compounds 
toward clinics but considering that their structure and pharmacological properties have been reported, they cannot be patented anymore and there is little interest from pharmaceutical industry to support expensive clinical trials with no lucrative returns on their investment.

\section{Trifluorothiazolines}

In 2014, Albericio, Gil, Lavilla and coworkers synthesized a series of cytotoxic trifluorothiazolines, including fluorizoline (11, Fig. 9, $\mathrm{EC}_{50}$ of 3.6 and $1.8 \mu \mathrm{M}$ in Jurkat and HeLa cells) [67]. Using an affinity chromatography approach, these authors identified PHB1 and PHB2 as the molecular target of these compounds.

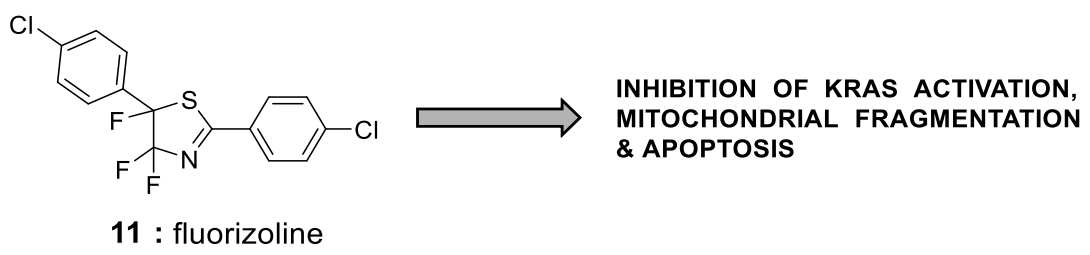

Fig. 9 Structure of fluorizoline (11).

Fluorizoline induces mitochondrial fragmentation, cristae disorganization and the intrinsic pathway of apoptosis in cancer cells [68-70]. Although this compound is cytotoxic in vitro in chronic lymphocytic leukemia cells, it is inactive in a murine model of leukemia [71].

Interestingly, similarly to flavaglines, fluorizoline inhibits epidermal growth factor (EGF)/RAS-induced CRAF activation [43]. However, the detailed mechanism between these 2 classes of PHB ligands differs. Indeed, in the opposite to flavaglines, fluorizoline does not prevent the localization of PHBs at the plasma membrane and the binding of GTP to KRAS in response to EGF [43].

\section{Melanogenin derivatives}

Using a cellular screening of a tagged-triazine library, Orlow and collaborators have identified a triazine called melanogenin as an inducer of melanogenesis, which upregulates tyrosinase, the rate-limiting enzyme in the biosynthesis of melanin [72]. This study uncovered the role of PHB in melanogenesis. Further pharmacomodulation studies recently led to the development of more active compounds, such as Mel9 (12) and Mel41 (13) (Fig. 10) [73]. Fluorizoline activates melanogenesis as well, confirming that this event is indeed mediated by PHBs. Mechanistic studies demonstrated that the binding of Mel9 and Mel41 to PHBs triggers a cascade of events that involves the autophagic factor LC3, the kinase ERK and the transcription factor MITF. LC3 is a protein involved in autophagy and melanogenesis [74]. Its cytosolic form (LC3-I) can be cleaved and conjugated to phosphatidylethanolamine to generate the active form LC3-II, which interacts with PHB2 in damaged mitochondria to induce a mitochondrial destruction by a processed known as mitophagy [54]. The discovery of Mel9 and Mel41 permitted to show that the regulation of melanogenesis by LC3-II is mediated by PHBs. It has also been found that LC3-II activates ERK, which triggers a cascade of events to 
promote the transcriptional activity of MITF, the master regulator of melanogenesis. This study highlights the power of small molecules as chemical probes to unravel PHBs signaling.

Interestingly, these new PHB ligands were shown to induce the death of a variety of human cancer cells [73]. Preliminary investigations showed that they inhibit the phosphorylation of the pro-survival kinase AKT, which probably contribute to this cytotoxicity.

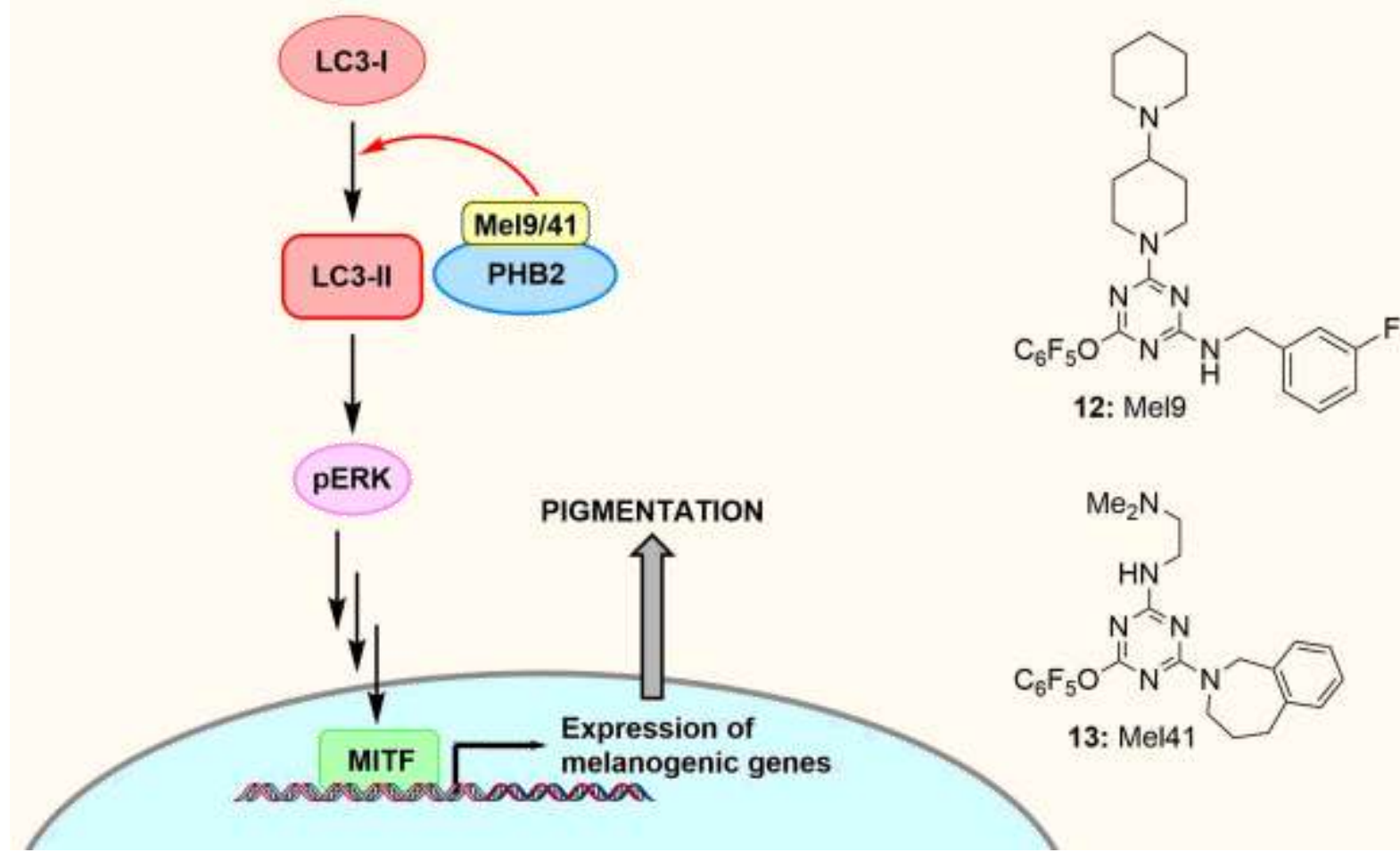

Fig. 10 Structure and mode of action of Mel9 and Mel41. The binding of Mel9 or Mel 41 to PHB2 promotes the conversion of LC3-I to LC3-II, which activates the kinase ERK, and though a cascade of events the transcriptional factor MITF to induce melanogenesis in melanocytes.

\section{JI130}

The transcription factor Hes family bHLH transcription factor 1 (Hes1) is an emerging target in oncology. While they were searching for inhibitors of Hes1 signaling, Uesugi, Kodama and collaborators identified D8C (14, Fig. 11) that significantly blocks Hes1 transcriptional activity and proliferation of HEK293 cells with an EC50 of $1.8 \mu \mathrm{M}$ [30]. These authors synthesized a series of 130 compounds and identified in particular two improved derivatives, JI051 (15) and JI130 (16), the latter one displaying an enhanced solubility in water. These authors have found that JI051 binds to PHB2 to stabilize the interaction between Hes1 and PHB2 outside the nucleus, and promotes G2/M cell cycle arrest. Importantly, JI130 reduced by half the tumor growth in a pancreatic tumor xenograft model. Whether this class of compounds modulates the interaction between PHB2 and some of its other partners remains an open question. 


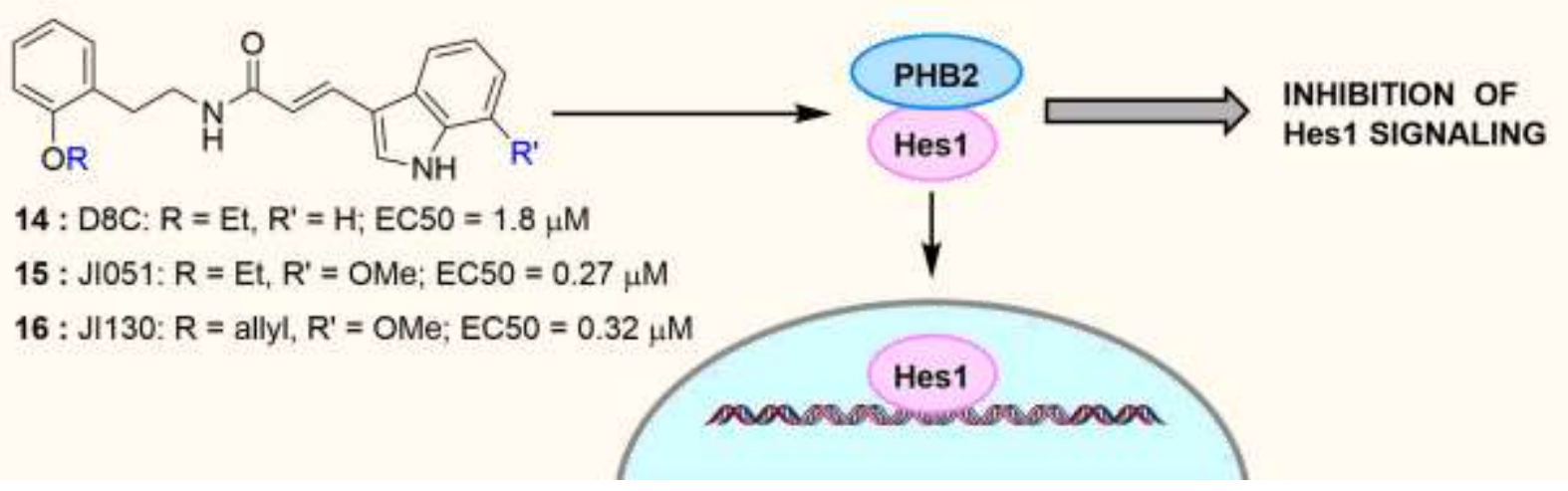

Fig. 11 Structure, mechanism of action and cytotoxicity in HEK293 cells of D8C, JI051 and JI130. The binding of these compounds to PHB2 promotes its interaction with the transcription factor Hes1 in the cytosol, thereby preventing its oncogenic transcriptional activity.

\section{Aurilide}

Aurilide (17, Fig. 12) is a cyclic depsipeptide isolated from a marine mollusk that blocks the PHBdependent inhibition of the proteolytic processing of the dynamin-like GTPase optic atrophy 1 (OPA1) leading to disintegration of mitochondria and consequently an extreme toxicity, which excludes any development as a medicament [75].

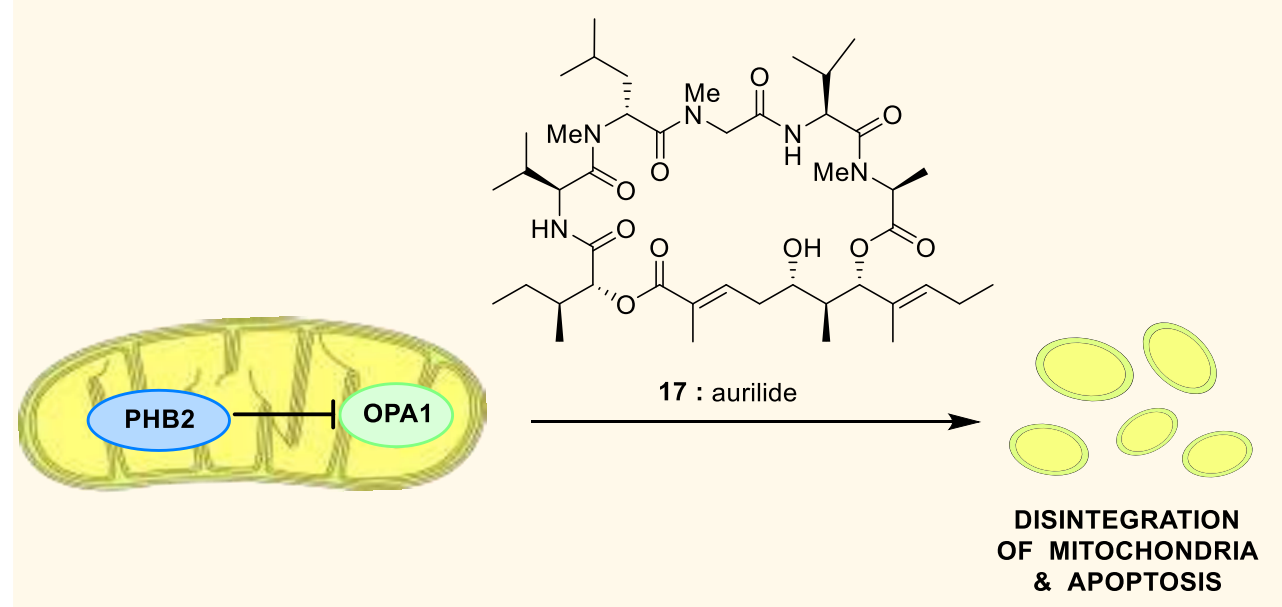

Fig. 12 Structure and mechanism of aurilide (17).

\section{Sulfonyl- and phosphoryl-amidines}

The current treatments of osteoporosis display some potential adverse effects and a limited efficacy on non-vertebral fracture reduction [76]. Due to these limitations and the ageing of the population, the discovery of new anti-osteoporotic agents is a matter of public health. In this context, Chang et al. have screened a library of sulfonyl- and phosphoryl-amidine for their in vitro ability to block the differentiation 
of pre-osteoclast into osteoclasts that mediate the removal of bone cells [77]. The phosphorylamidine 18 and the sulfonylamidine 19 (Fig. 13) were found to be particularly potent inhibitors of osteoclast differentiation with an IC50 of 2.6 and $3.3 \mu \mathrm{M}$ respectively. They also block the bone resorbing activity of mature osteoclasts. Using affinity chromatography, PHB1 has been identified as the molecular target of these compounds [78]. Since then, PHB1 has been demonstrated to inhibit the formation of mature osteoclasts [79]. Although the engagement of PHB1 in the activity of $\mathbf{1 8}$ and $\mathbf{1 9}$ has not been established yet, some key events in the mechanism of action of these compounds have been clarified [80]. Osteoclast differentiation is initiated by the binding of RANK ligand (RANKL) to RANK, which activates TRAF6 and consecutively, IKK and ERK, leading to the activation of the transcription factors NF-KB, c-Fos and NFATc1 (Fig. 13). Compound 18 has been shown to dose-dependently inhibit the RANKL-induced activation of ERK, and both the translocation to the nucleus and the transcriptional activity of NF-KB. In addition, 18 repressed the mRNA expression levels of c-Fos and NFATc1 induced by RANKL, indicating that 18 mitigates RANKL-induced signaling and transcription factors required for osteoclast differentiation. Compound $\mathbf{1 8}$ also repressed the expression of the matrix metalloproteinase 9 (MMP-9) and the kinase c-Src that both promote osteoclastic bone resorption. In vivo, 18 (daily $100 \mathrm{mg} / \mathrm{kg}$ for 4 weeks) restores the loss of trabecular bone in the femur of ovariectomized mice, comforting its potential for the treatment of osteoporosis.

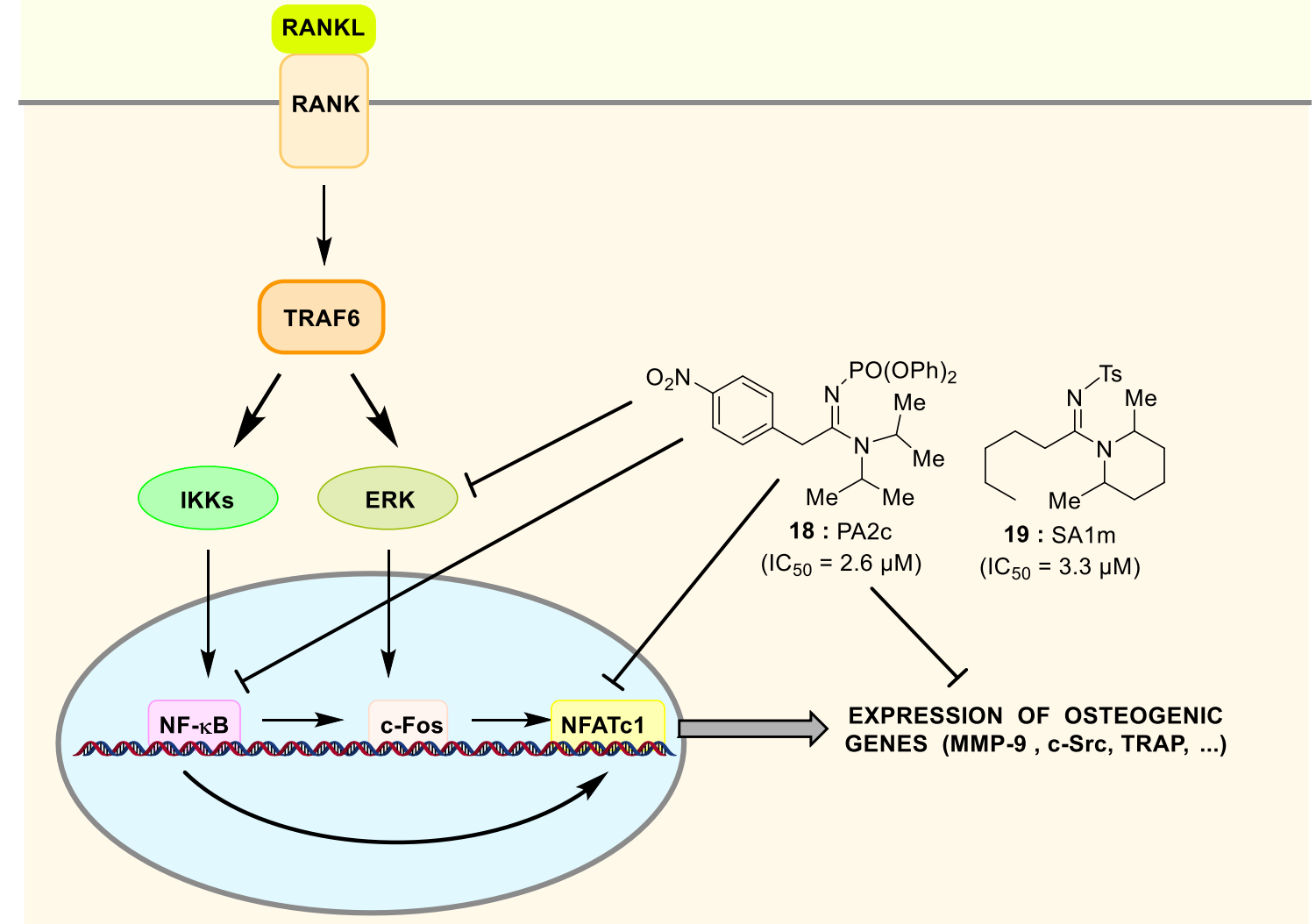

Fig. 13 Structure of the phosphoryl- and sulfonyl-amidines 18 and 19 and overview of their mechanism of inhibition of osteoclastogenesis. Compound $\mathbf{1 8}$ inhibits the activation of ERK, the translocation of NF- 
$\mathrm{KB}$ to the nucleus and also the expression of osteogenic genes (the transcription factors c-Fos and NFATc1, the matrix metalloproteinase 9 (MMP-9) and the kinase c-Src).

Similarly to the flavagline FL3, sulfonylamidine $\mathbf{1 9}$ was also shown to block the PHB-dependent entry of Chikungunya virus into microglial cells [57], indicating that this type of PHB ligand may exhibit various pharmacological effects unrelated to osteoclastogenesis.

\section{Adipotide}

Adipotide results from a sequence homologous to the region of annexin A2 fused to proapoptotic sequence tissue [81]. This chimeric peptide interacts with PHB1 at the surface the endothelial cells of adipose tissue to destroy the vasculature of this tissue and consequently alter its blood supply. Adipotide reduces body weight in fat mice and rats exposed to a high-fat diet. In obese rhesus monkeys, adipotide also lowers body fat, food intake and insulin resistance [82]. However, the absence of additional report since 2012 suggests that this approach hold serious limitations for a clinical development to treat type 2 diabetes.

\section{Vi polysaccharide of Salmonella typhi}

Vi capsular polysaccharide (Vi) (20, Fig. 14A) of Salmonella typhi, the causative agent of typhoid fever interacts with cell surface PHBs to inhibit ERK activity and interleukin-8 secretion in human intestinal epithelial cells (Fig. 13) [83]. As a consequence the early inflammatory response from intestinal epithelium is down regulated causing systemic infection in humans [84]. In monocytes and T-cells, Vi also inhibits the GTPases Rac1 and Cdc42, NF-KB signaling, ERK pathways and actin cytoskeletal rearrangements to inhibit the inflammatory response. Interestingly, the binding of Vi released by S. Typhi on the membrane PHBs blocks IL-2 secretion from T cells stimulated through the T-cell receptor (TCR) but not Protein Kinase C [85]. None of these events are observed in Salmonella, such as Salmonella typhimurium, that do not synthesize $\mathrm{Vi}[86,87,85]$. 

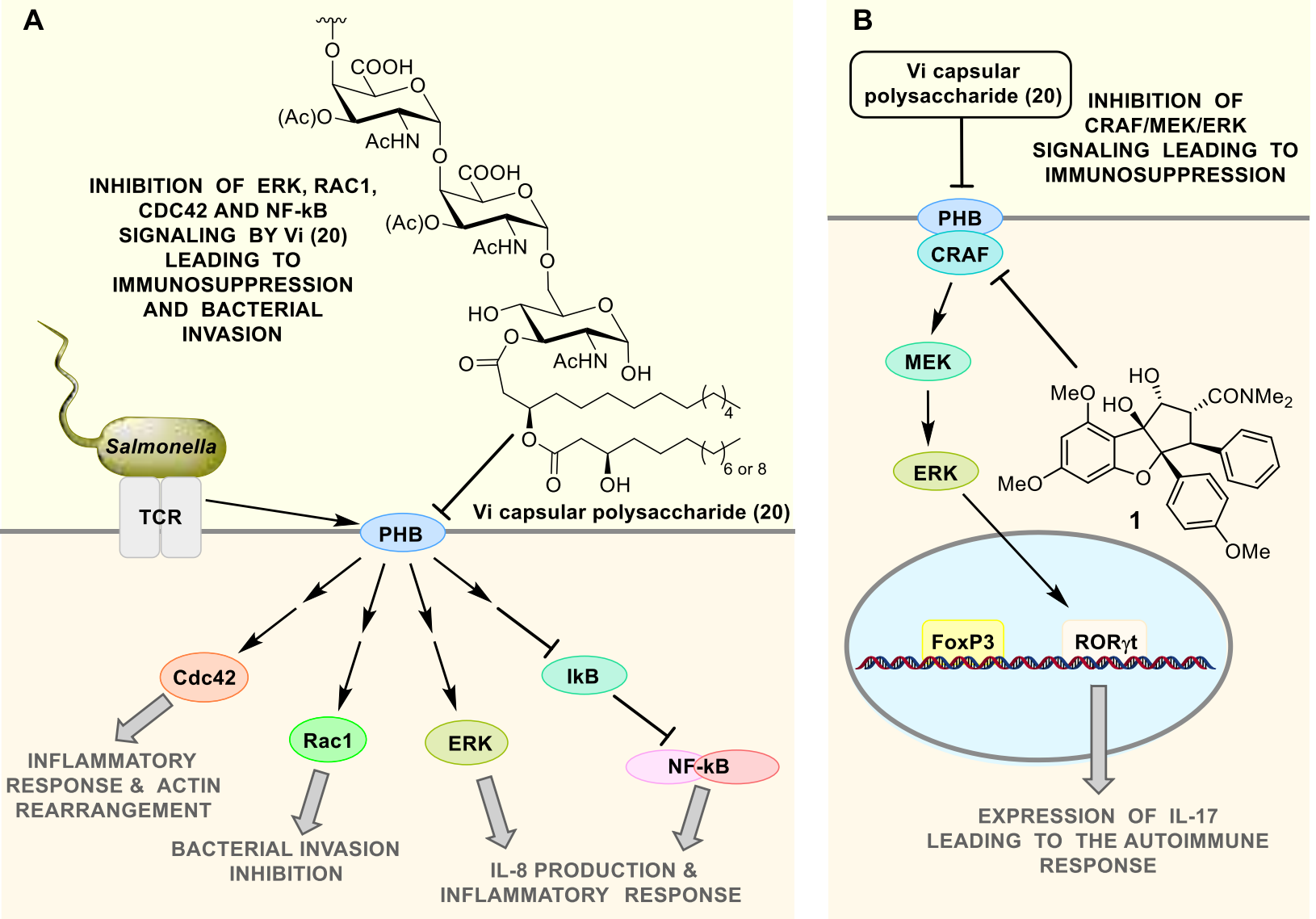

Fig. 14 Structure of Vi polysaccharide (20) and overview of its mechanism of immunosuppression during typhoid infection and in multiple sclerosis. A) Salmonella activates the kinase ERK, small Rho family GTPases, Cdc42, and Rac-1 to induce inflammation. Vi released by Salmonella interacts with PHBs to block the activation of ERK, Cdc42 and Rac-1 resulting in reduced invasion of cells with Salmonella and inhibition of inflammatory responses. B) Mechanism of immunosuppression of $\mathrm{Vi} \mathrm{(20)}$ and rocaglamide (1) in Thelper 17 cells in multiple sclerosis.

In line with this study, K. Rajalingam and coll. recently reported that Vi capsular polysaccharide can alleviate multiple sclerosis symptoms in mice (Fig. 14B) [14]. Importantly, the cell surface of CD4 ${ }^{+} \mathrm{T}$ cell has been found to overexpress PHB1 in blood samples from multiple sclerosis patients in comparison with healthy persons. Among the different subsets of $\mathrm{CD}^{+}{ }^{+} \mathrm{T}$ cells, $\mathrm{T}$ helper (Th)17 cells are particularly involved in the etiology of autoimmune diseases due to their capacity to produce interleukin (IL)-17. These cells overexpress PHB1 at the cell surface to activate the C-RAF/MEK/ERK pathways and regulate the activity of the transcriptions factors FOXP3 and RORyt leading to the pathogenic expression of IL-17. Both Vi polysaccharide, which is used as a vaccine (Typhim) against Salmonella enterica infections, and rocaglamide have been shown to block these events in vitro and in a mouse model of multiple sclerosis. 


\section{Lipoteichoic acid}

PHB2 was shown to bind to another polyanionic bacterial lipid, lipoteichoic acid (21, Fig. 15) a cell wall constituent of gram-positive bacteria [88]. Even though the consequence of this binding has not been disclosed yet, this observation highlights the implication of PHBs in the immune response to infections. Interestingly, lipoteichoic acid has been shown to activate RAF in the cornea, but whether this involves PHBs has not been documented yet [89].

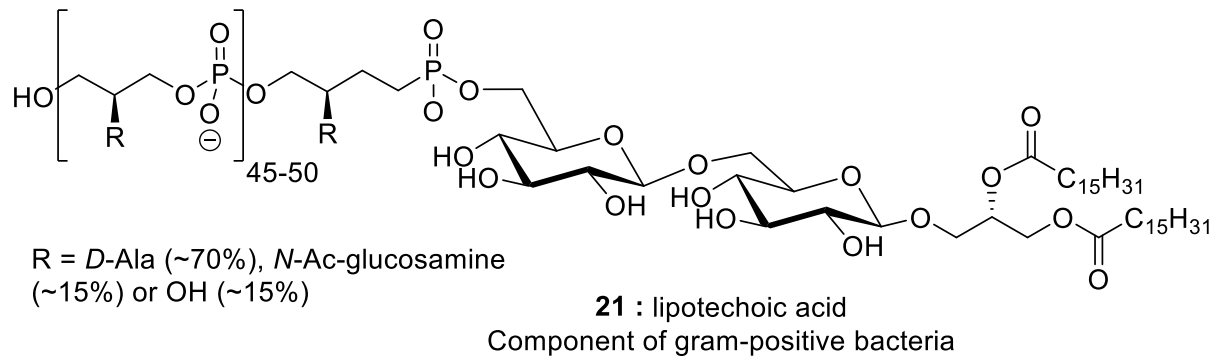

Fig. 15 Structure of lipoteichoic acid (21).

\section{Capsaicin}

Capsaicin (22, Fig. 16) is a component of hot chili peppers that shares some structural and pharmacological properties with JI130 [90]. Indeed, it also binds to PHB2 to promote its translocation from mitochondria to the nucleus, dissociating it from the Adenine Nucleotide Translocator 2 (ANT2). Thus, it initiates the mitochondrial apoptosis in human myeloid leukemia cells. The concentration of capsaicin used in this experiment was too high to be pertinent for therapeutic purpose, but this work may constitute the basis for an optimization program to develop a clinically useful drug.
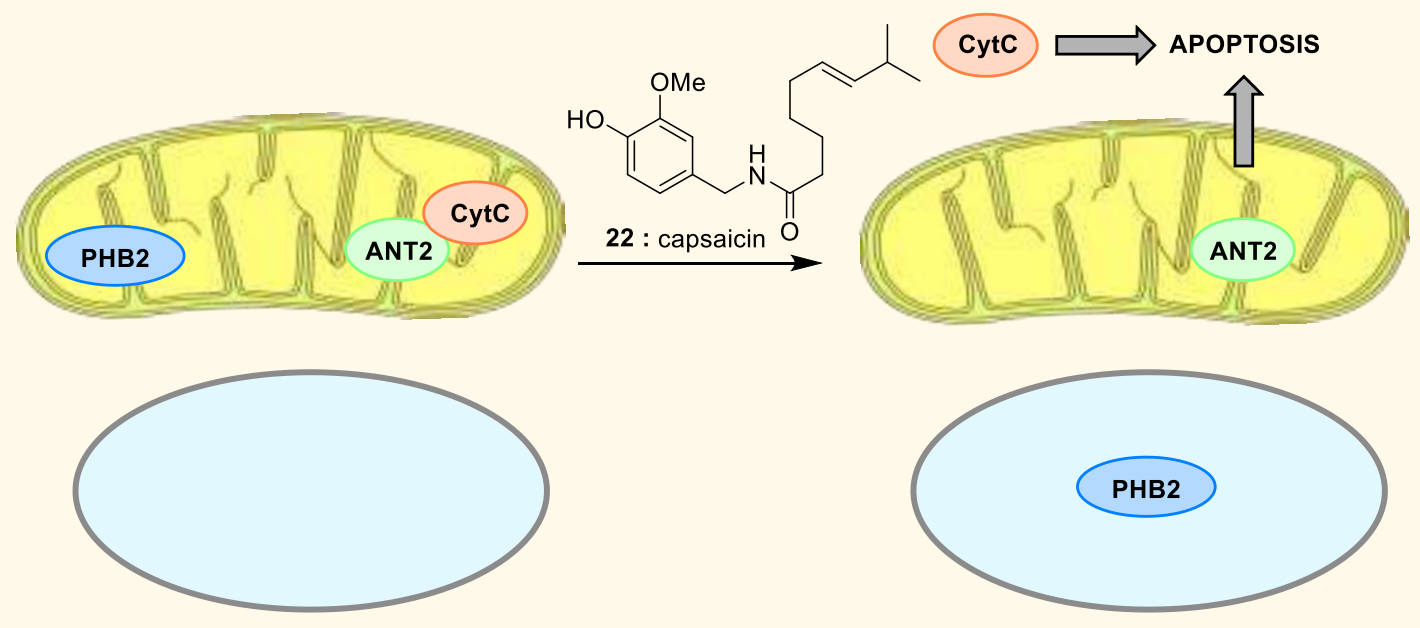

Fig. 16 Structure and cytotoxicity mechanism of capsaicin (22) in myeloid leukemia cells. Capsaicin induces the translocation to the nucleus of PHB2, which is normally localized to the inner mitochondrial membrane. 


\section{Xanthohumol}

Xanthohumol (23, Fig. 17), a polyphenol found in hops, binds to PHB2 to inhibit its binding to Brefeldin Ainhibited guanine nucleotide exchange protein 3 (BIG3), which suppresses the inhibitory activity of PHB2 on the estrogen receptor alpha (ER $\alpha)$ in breast cancer cells [91]. Thus, the binding of xanthohumol has been shown to block ER $\alpha$-positive breast cancer cell growth both in vitro and in vivo. However, the polyphenolic structure of this natural compound coupled to its moderate potency precludes its development as a drug candidate.

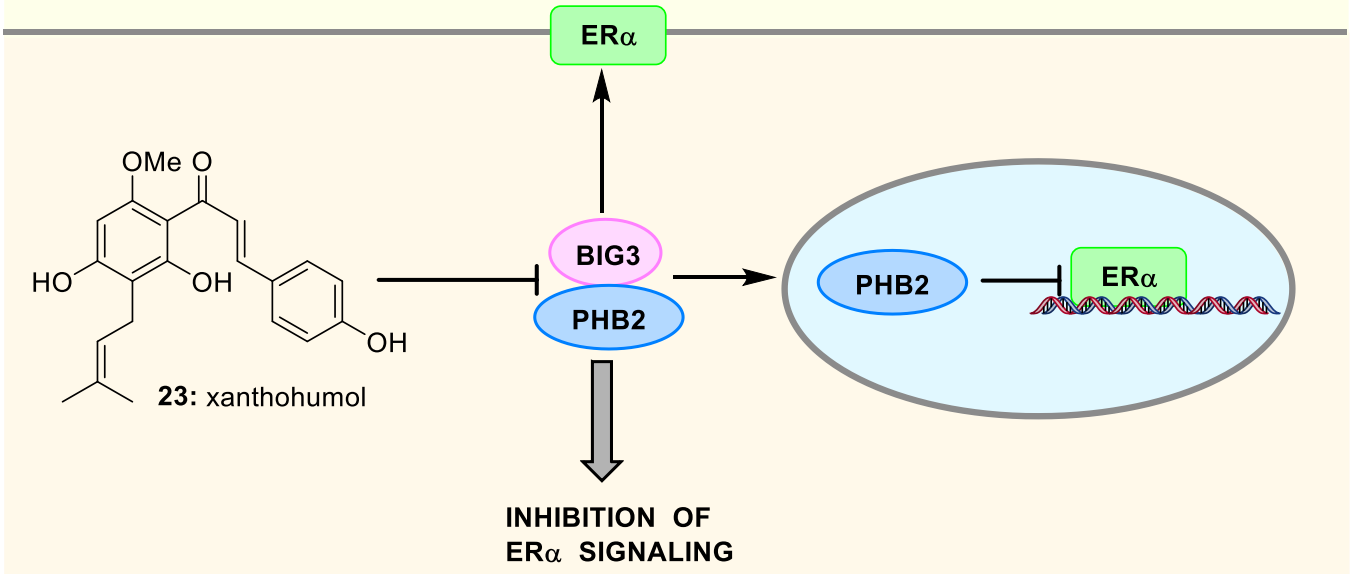

Fig. 17 Structure and mechanism of action of xanthohumol (23). Xanthohumol binds to PHB2, thereby preventing its interactions with BIG3. Free PHB2 directly binds to both nuclear and membraneassociated ER $\alpha$ to inhibit their activity.

\section{Spiro-oxindoles}

The spiro-oxindole 24 (Fig. 18) has been found to bind to 7 different proteins, including PHB2 [92]. Further studies showed that this compound exists as a mixture of two regioisomers 24a and 24b in equilibrium, and that the introduction of an allyl or an isobutyl on the pyrrolidine nitrogen (25 and 26) blocks this epimerization [93]. Interestingly, similarly to flavaglines, these compounds protect cardiomyocytes against the toxicity of doxorubicin. Mechanistic studies showed that these compounds bind to both PHB1 and PHB1 and induce the phosphorylation of STAT3 to promote cardiomyocyte survival. 


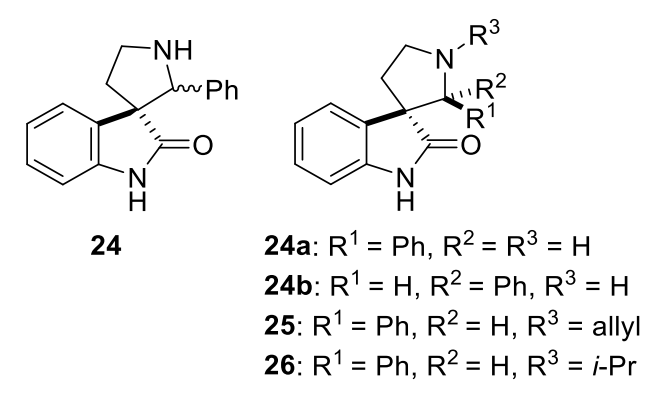

Fig. 18 Structure of spiro-oxindoles 24-26.

\section{Adenine derivatives Aftin-4 and PDD005}

Amyloid-beta $(A \beta)$ peptides generate the amyloid plaques in the brain of patients suffering from Alzheimer's disease and Parkinson's disease dementia. These neurodegenerative diseases are also characterized by hyperphosphorylation of tau protein, progressive neuronal loss, neuroinflammation, and impairment of neurogenesis.

An adenine derivative, Aftin-4 (27, Fig. 19), was found to promote the production of the toxic amyloid$\beta 42$ (A 342 ) peptide in vitro and in vivo, resulting in a rapid and severe Alzheimer's syndrome in the mouse brain $[94,95]$. Further investigation showed that this compound binds to PHB1 along with VDAC1 and mitofilin.

Thereafter, an analogue, PDD005 (28), was found to display opposite effects [96]. Indeed it rescues cognitive deficits associated with aging in mice. Not in only it alleviates neurogenesis deficiency by upregulating the expression of neurotrophic factors, but, similarly to flavaglines IMD-019064 and IMD026259 (7, 8, Fig. 3, [63]), it also inhibits neuro-inflammation. This neuroprotectant activity is also manifested by a reduction of tau phosphorylation in aging mice.

PDD005 was shown to interact with PHB1 and PHB2 with a kD of $9.5 \pm 4.6 \mu \mathrm{M}$ and $1.29 \pm 1.16 \mu \mathrm{M}$, respectively (determined by microscale thermophoresis). Interestingly, PDD005-treatment significantly enhances the expression of PHB1 and PHB2 in the hippocampal dentate gyrus of aged mouse. It also increases about 1.5 times the phosphorylation of GSK-3 $\beta$ in organotypic hippocampal slice cultures, suggesting that this signaling protein is involved, at least partially, in the mechanism of neuroprotection. 


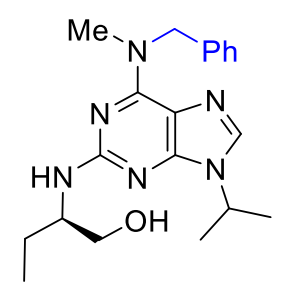

27 : Aftin-4 Neurotoxic

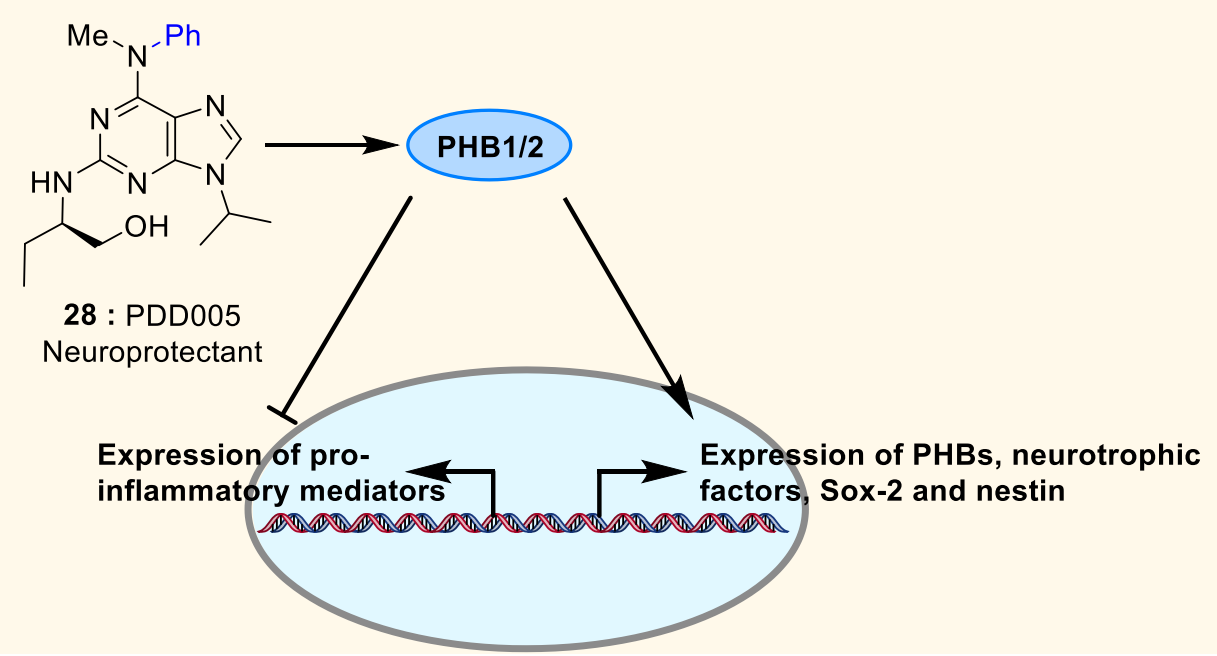

Fig. 19 Structure of Aftin-4 (27) and PDD005 (28) and mechanism of PDD005 neuroprotection in neurons, astrocytes and microglia.

\section{Concluding remarks and future directions}

PHBs regulate a myriad of signaling pathways in every cell of the body, which constitutes both a threat and an opportunity. A threat, because a pessimist would expect unacceptable adverse effects for any drug candidate targeting PHBs. An opportunity, because an optimist would consider that such a candidate might be used to treat several types of diseases. Indeed, known PHB ligands have been shown to display a significant efficacy in mouse models of cancers, Parkinson disease, cardiac damage, Crohn's disease, and osteoporosis. The coming decade will probably uncover the potential PHB ligands for other types of ailments. One may wonder why the different classes of PHB ligands display very different profiles of pharmacological activities. The answer is probably multiple. First, some drugs may be selective of PHB1 or PHB2 (Fig. 20A). Second, some ligands may preferentially interact with forms of PHBs harboring specific post-translational modifications (Ser and Tyr phosphorylations, palmitoylations, ..., Fig. 20B). Third, even for each specific form of post-translationally modified PHB, two different ligands may form dissimilar interactions to stabilize the PHB in different conformations and modulate its interaction with its proteins partners, including the enzymes that are responsible for the post-translational modifications of PHBs (Fig. 20C). And finally, some compounds may target PHBS and additional proteins, such as elF4A for flavaglines for example (Fig. 20D). 
A

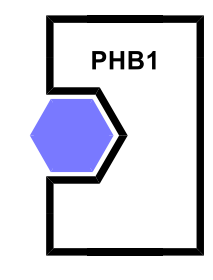

PHB1 selective ligand

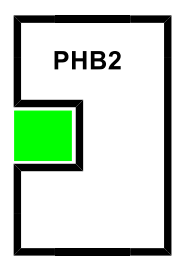

PHB2 selective ligand
B

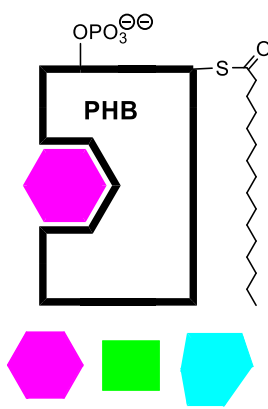

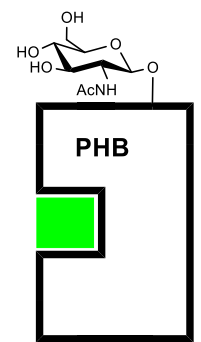

ligands selective for a $\mathrm{PHB}$ harhoring specific post-translational modifications

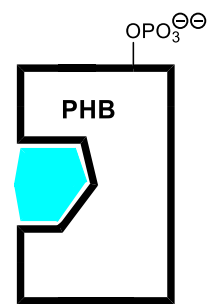

D
C

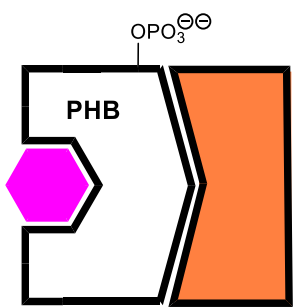

ligands stabilizing different conformations of PHB harboring identical post-translational modifications leading to interaction with different proteins
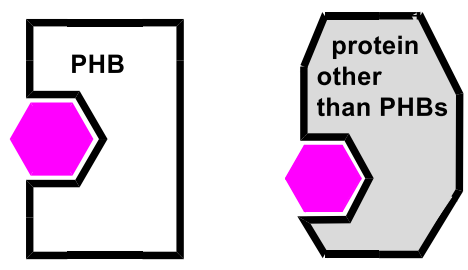

ligand for PHB1/2 and (an)other protein(s)

Fig. 20 Proposed explanation why various classes of PHB ligand display different pharmacological profiles.

Except of aurilide that induces the disintegration of mitochondria [80], most of the PHB ligands do not seem to perturb critical functions in non-cancer cells, which explain why they do not display a strong acute toxicity at their active doses in mice. However, as far as we know, no study focusing on the toxicity of these drugs has been disclosed yet. Nonetheless, a critical step to advance them to clinics will be to define their on-target and off-target acute and chronic toxicity profile to optimize their therapeutic index.

In addition to small molecules, antibodies represent an effective class of medicines for targeted therapies. However, using an antibody targeting PHB1 may be problematic. Indeed, a quarter of patients suffering from Behcet's disease, but not healthy controls, express PHB1 autoantibodies, suggesting that anti-PHB1 antibody may induce severe blood vessel inflammation [97].

Even though, no PHB ligand has entered a clinical trial yet, this class of drug has already found some utility to decipher PHB signaling in different physiological and pathological settings, such as cancer cell metabolism and survival, inflammation, cardioprotection, neuroprotection and viral infection. The growing numbers of reports on PHB functions in physiology and pathophysiology should stimulate the development new PHB ligands and possibly lead to a clinical candidate in the future.

\section{ACKNOWLEDGMENTS}


Financial support from the National Natural Science Foundation of China (No. 81673296) and the startup Foundation from Tianjin University of Science \& Technology is gratefully acknowledged. KR acknowledges support from DFG and CRC1292.

Table 1 Post-translational regulation of PHBs.

\begin{tabular}{|c|c|c|}
\hline Post-translational modification & Consequence & References \\
\hline \multicolumn{3}{|l|}{ PHB1 } \\
\hline Phosphorylation at Thr 258 by Akt & $\begin{array}{l}\text { Inhibition of the interaction of PHB1 with } \\
\text { PIP3 and Shp2. } \\
\text { Localization of PHB1 in mitochondria to } \\
\text { promote cell survival }\end{array}$ & $\begin{array}{l}{[9]} \\
{[98]}\end{array}$ \\
\hline $\begin{array}{l}\text { Phosphorylation at Thr } 258 \text { induced by PGE2 } \\
\text { or growth factors such as EGF, HGF and IGF-1 }\end{array}$ & $\begin{array}{l}\text { Interaction of PHB1 with Ras, phospho- } \\
\text { Akt(Ser 473), phospho-Raf-1(Ser 338), } \\
\text { MEKK1 and IKK } \alpha / \beta(\text { Ser } 176 / 180) \text { in the raft } \\
\text { domain }\end{array}$ & {$[47]$} \\
\hline $\begin{array}{l}\text { Phosphorylation at Tyr } 114 \text { by the insulin } \\
\text { receptor }\end{array}$ & $\begin{array}{l}\text { Interaction with } \mathrm{SH} 2 \text { domain containing } \\
\text { tyrosine phosphatase-1 (Shp1) leading to a } \\
\text { desensitization of insulin signaling }\end{array}$ & [99] \\
\hline $\begin{array}{l}\text { Phosphorylation of Tyr 249, Thr } 258 \text { and Tyr } \\
259 \text { by MEK1 and p38MAPK in response to } \\
\text { FSH stimulation }\end{array}$ & $\begin{array}{l}\text { Localization of PHB1 in mitochondria to } \\
\text { promote cell survival and differentiation of } \\
\text { ovarian granulosa cells }\end{array}$ & {$[100]$} \\
\hline Phosphorylation at Tyr 114 and Tyr 259 by Lyn & $\begin{array}{l}\text { Formation of a ternary complex consisting } \\
\text { of PHB1, the IgE receptor FcERI and the } \\
\text { kinase Syk that triggers mast cell activation }\end{array}$ & [13] \\
\hline $\begin{array}{l}\text { Palmitoylation at its only cysteine residue (Cys } \\
\text { 69) }\end{array}$ & $\begin{array}{l}\text { Translocation of PHB1 to the plasma } \\
\text { membrane } \\
\text { Interaction with Eps } 15 \text { homology domain } \\
\text { protein } 2 \text { (EHD2). }\end{array}$ & $\begin{array}{l}{[13]} \\
{[101]}\end{array}$ \\
\hline $\begin{array}{l}\text { Phosphorylation by PKC (possibly at } \\
\text { at Ser } 8 \text {, Ser } 129, \text { Thr } 155 \text { ) }\end{array}$ & $\begin{array}{l}\text { Localization of PHB1 in mitochondria to } \\
\text { promote cell survival }\end{array}$ & {$[102]$} \\
\hline Phosphorylation by both MEK1 and PKC-delta & $\begin{array}{l}\text { Promotion of cell survival and invasion and } \\
\text { inhibition of inner mitochondrial } \\
\text { permeability }\end{array}$ & [102] \\
\hline
\end{tabular}


Phosphorylation at Ser 82 and Ser 218 by Regulation of mitosis

Aurora and/or Polo-Like Kinase

Conjugation to $O$-GIcNAc by $O$-GlcNAc Suppression of the phosphorylation at Tyr [104]

transferase at Ser121 and Thr258 in response residues in the vicinity of this modification

to hyperglycemia

Tyrosine nitrosylation

Associated with mitochondrial dysfunction

[105]

Ubiquitination by E3 ligase TRIM21

Degradation of PHB1. A tumor suppressor,

[106]

LPLUNC1, stabilizes PHB1 by inhibiting its

ubiquitination

Transamidation by Transglutaminase 2 (TG2)

Involvement in insulin secretion

[107-109]

of Gln residues with some primary amines, including interacting proteins

Cross-link with interacting mitochondrial

proteins to promote neuroprotection

$\begin{aligned} & \text { Oxidation at Cys69 by ROS upon alcohol } \begin{array}{l}\text { Possible induction of mitochondrial [110] } \\ \text { exposure }\end{array} \\ & \text { dysfunction and cellular injury }\end{aligned}$

Deimination of an Arg residue by Possible modulation of PHB1 function and [111]

peptidylarginine deiminases

involvement in cancer etiology

Ubiquitination by Skp2B

Degradation of PHB1 leading to a defect in

[112-114]

the activity of $\mathrm{p} 53$

\section{PHB2}

Phosphorylation at Ser 105, Ser 151, Ser 243 Regulation of mitosis

[103]

and Ser 286 by Aurora and/or Polo-Like Kinase

Phosphorylation at Ser 91 and Ser 176 by Akt Involvement in all-trans retinoic acid- [115]

induced differentiation of human acute

promyelocytic leukemia cells

Phosphorylation at Ser 91 by CaMK IV

Repression of MEF2 transcriptional activity [116]

to inhibit muscle differentiation.

Phosphorylation at Tyr 248, possibly by Akt, Undetermined

[117]

RSK, S6 or TnK1

Phosphorylation at Tyr 128

Associated with cancer (identified during

[118] 
phosphotyrosine profiling of cancer cell

proteome)

Phosphorylation at Ser 39 by PKCa

Suppression of ER $\alpha$ signalling

[119]

Dephosphorylation at Ser 39 by PP1C $\alpha$ Activation of ER $\alpha$ signalling

[119]

complexed to guanine nucleotide-exchange

protein 3 (BIG3).

\section{AUTHOR CONTRIBUTIONS}

All authors contributed to the writing of this review.

\section{REFERENCES}

1. Ande SR, Xu YXZ, Mishra S (2017) Prohibitin: a potential therapeutic target in tyrosine kinase signaling. Signal Transduct Target Ther 2:17059. doi:10.1038/sigtrans.2017.59

2. Chowdhury D, Kumar D, Sarma P, Tangutur AD, Bhadra MP (2017) PHB in Cardiovascular and Other Diseases: Present Knowledge and Implications. Curr Drug Targets 18 (16):1836-1851. doi:10.2174/1389450117666160824161225

3. Koushyar S, Jiang WG, Dart DA (2015) Unveiling the potential of prohibitin in cancer. Cancer Lett 369 (2):316-322. doi:10.1016/j.canlet.2015.09.012

4. Peng YT, Chen P, Ouyang RY, Song L (2015) Multifaceted role of prohibitin in cell survival and apoptosis. Apoptosis 20 (9):1135-1149. doi:10.1007/s10495-015-1143-z

5. Theiss AL, Sitaraman SV (2011) The role and therapeutic potential of prohibitin in disease.

Biochim Biophys Acta 1813 (6):1137-1143. doi:10.1016/j.bbamcr.2011.01.033

6. Thuaud F, Ribeiro N, Nebigil CG, Desaubry L (2013) Prohibitin ligands in cell death and survival: mode of action and therapeutic potential. Chem Biol 20 (3):316-331.

doi:10.1016/j.chembiol.2013.02.006

7. Sripathi SR, Sylvester O, He WL, Moser T, Um JY, Lamoke F, Ramakrishna W, Bernstein PS, Bartoli M, Jahng WJ (2016) Prohibitin as the Molecular Binding Switch in the Retinal Pigment Epithelium. Protein J 35 (1):1-16. doi:10.1007/s10930-015-9641-y

8. Yoshinaka T, Kosako H, Yoshizumi T, Furukawa R, Hirano Y, Kuge O, Tamada T, Koshiba T (2019) Structural Basis of Mitochondrial Scaffolds by Prohibitin Complexes: Insight into a Role of the Coiled-Coil Region. iScience 19:1065-1078. doi:10.1016/j.isci.2019.08.056

9. Ande SR, Mishra S (2009) Prohibitin interacts with phosphatidylinositol 3,4,5-triphosphate (PIP3) and modulates insulin signaling. Biochem Biophys Res Commun 390 (3):1023-1028.

doi:10.1016/j.bbrc.2009.10.101

10. Gomez L, Paillard M, Price M, Chen Q, Teixeira G, Spiegel S, Lesnefsky EJ (2011) A novel role for mitochondrial sphingosine-1-phosphate produced by sphingosine kinase-2 in PTPmediated cell survival during cardioprotection. Basic Res Cardiol 106 (6):1341-1353.

doi:10.1007/s00395-011-0223-7

11. https://www.phosphosite.org/homeAction. https://www.phosphosite.org/homeAction. 
12. Yurugi H, Tanida S, Akita K, Ishida A, Toda M, Nakada H (2013) Prohibitins function as endogenous ligands for Siglec-9 and negatively regulate TCR signaling upon ligation. Biochem Biophys Res Commun 434 (2):376-381. doi:10.1016/j.bbrc.2013.03.085

13. Kim DK, Kim HS, Kim AR, Jang GH, Kim HW, Park YH, Kim B, Park YM, Beaven MA, Kim YM, Choi WS (2013) The Scaffold Protein Prohibitin Is Required for Antigen-Stimulated Signaling in Mast Cells. Science Signaling 6 (292). doi:10.1126/scisignal.2004098

14. Buehler U, Schulenburg K, Yurugi H, Šolman M, Abankwa D, Ulges A, Tenzer S, Bopp T, Thiede B, Zipp F, Rajalingam K (2018) Targeting prohibitins at the cell surface prevents Th17mediated autoimmunity. The EMBO Journal. doi:10.15252/embj.201899429

15. Patel N, Chatterjee SK, Vrbanac V, Chung I, Mu CJ, Olsen RR, Waghorne C, Zetter BR (2010) Rescue of paclitaxel sensitivity by repression of Prohibitin1 in drug-resistant cancer cells. Proc Natl Acad Sci U S A 107 (6):2503-2508. doi:10.1073/pnas.0910649107

16. Fusaro G, Dasgupta P, Rastogi S, Joshi B, Chellappan S (2003) Prohibitin induces the transcriptional activity of p53 and is exported from the nucleus upon apoptotic signaling. J Biol Chem 278 (48):47853-47861. doi:10.1074/jbc.M305171200

17. Gamble SC, Chotai D, Odontiadis M, Dart DA, Brooke GN, Powell SM, Reebye V, VarelaCarver A, Kawano Y, Waxman J, Bevan CL (2007) Prohibitin, a protein downregulated by androgens, represses androgen receptor activity. Oncogene 26 (12):1757-1768. doi:10.1038/sj.onc. 1209967

18. Joshi B, Rastogi S, Morris M, Carastro LM, Decook C, Seto E, Chellappan SP (2006) Differential regulation of human YY1 and caspase 7 promoters by prohibitin through E2F1 and p53 binding sites. Biochemical Journal 401 (1):155-166. doi:10.1042/bj20060364

19. Lee SJ, Choi D, Rhim H, Choo HJ, Ko YG, Kim CG, Kang S (2008) PHB2 interacts with RNF2 and represses CP2c-stimulated transcription. Mol Cell Biochem 319 (1-2):69-77. doi:10.1007/s11010-008-9878-2

20. Montano MM, Ekena K, Delage-Mourroux R, Chang W, Martini P, Katzenellenbogen BS (1999) An estrogen receptor-selective coregulator that potentiates the effectiveness of antiestrogens and represses the activity of estrogens. Proc Natl Acad Sci U S A 96 (12):69476952. doi:10.1073/pnas.96.12.6947

21. Sun L, Liu L, Yang XJ, Wu Z (2004) Akt binds prohibitin 2 and relieves its repression of MyoD and muscle differentiation. J Cell Sci 117 (Pt 14):3021-3029. doi:10.1242/jcs.01142 22. Wang S, Fusaro G, Padmanabhan J, Chellappan SP (2002) Prohibitin co-localizes with Rb in the nucleus and recruits $\mathrm{N}-\mathrm{CoR}$ and $\mathrm{HDAC} 1$ for transcriptional repression. Oncogene 21 (55):8388-8396. doi:10.1038/sj.onc.1205944

23. Wang S, Nath N, Adlam M, Chellappan S (1999) Prohibitin, a potential tumor suppressor, interacts with RB and regulates E2F function. Oncogene 18 (23):3501-3510. doi:10.1038/sj.onc. 1202684

24. Wang S, Nath N, Fusaro G, Chellappan S (1999) Rb and prohibitin target distinct regions of E2F1 for repression and respond to different upstream signals. Mol Cell Biol 19 (11):7447-7460. doi:10.1128/mcb.19.11.7447

25. Ramani K, Mavila N, Ko KS, Mato JM, Lu SC (2016) Prohibitin 1 Regulates the H19-Igf2 Axis and Proliferation in Hepatocytes. J Biol Chem 291 (46):24148-24159.

doi:10.1074/jbc.M116.744045

26. Fan W, Yang H, Liu T, Wang J, Li TW, Mavila N, Tang Y, Yang J, Peng H, Tu J, Annamalai A, Noureddin M, Krishnan A, Gores GJ, Martinez-Chantar ML, Mato JM, Lu SC (2017) Prohibitin 1 suppresses liver cancer tumorigenesis in mice and human hepatocellular and cholangiocarcinoma cells. Hepatology 65 (4):1249-1266. doi:10.1002/hep.28964 
27. Yang H, Li TW, Zhou Y, Peng H, Liu T, Zandi E, Martinez-Chantar ML, Mato JM, Lu SC (2015) Activation of a novel c-Myc-miR27-prohibitin 1 circuitry in cholestatic liver injury inhibits glutathione synthesis in mice. Antioxid Redox Signal 22 (3):259-274.

doi:10.1089/ars.2014.6027

28. Rizwani W, Alexandrow M, Chellappan S (2009) Prohibitin physically interacts with MCM proteins and inhibits mammalian DNA replication. Cell Cycle 8 (10):1621-1629.

doi:10.4161/cc.8.10.8578

29. Han J, Yu C, Souza RF, Theiss AL (2014) Prohibitin 1 modulates mitochondrial function of Stat3. Cell Signal 26 (10):2086-2095. doi:10.1016/j.cellsig.2014.06.006

30. Perron A, Nishikawa Y, Iwata J, Shimojo H, Takaya J, Kobayashi K, Imayoshi I, Mbenza

NM, Takenoya M, Kageyama R, Kodama Y, Uesugi M (2018) Small-molecule screening yields a compound that inhibits the cancer-associated transcription factor Hes1 via the PHB2 chaperone. J Biol Chem 293 (21):8285-8294. doi:10.1074/jbc.RA118.002316

31. Qureshi R, Yildirim O, Gasser A, Basmadjian C, Zhao Q, Wilmet JP, Desaubry L, Nebigil CG (2015) FL3, a Synthetic Flavagline and Ligand of Prohibitins, Protects Cardiomyocytes via STAT3 from Doxorubicin Toxicity. PLoS One 10 (11):e0141826.

doi:10.1371/journal.pone.0141826

32. Guan X, Liu Z, Wang L, Johnson DG, Wei Q (2014) Identification of prohibitin and prohibiton as novel factors binding to the p53 induced gene 3 (PIG3) promoter (TGYCC)(15) motif. Biochem Biophys Res Commun 443 (4):1239-1244. doi:10.1016/j.bbrc.2013.12.124 33. Zhang Y, Wang L-N, Lin Y-N, Xing Y-X, Shi Y, Zhao J, Chen W-W, Han B (2018) The novel long noncoding RNA LOC283070 is involved in the transition of LNCaP cells into androgen-independent cells via its interaction with PHB2. Asian Journal of Andrology 20 (5):511-517. doi:10.4103/aja.aja_36_18

34. Signorile A, Sgaramella G, Bellomo F, De Rasmo D (2019) Prohibitins: A Critical Role in Mitochondrial Functions and Implication in Diseases. Cells 8 (1). doi:10.3390/cells8010071 35. King ML, Chiang CC, Ling HC, Fujita E, Ochiai M, McPhail AT (1992) X-Ray crystal structure of rocaglamide, a novel antileukemic $1 \mathrm{H}$-cyclopenta[b]benzofuran from Aglaia elliptifolia. Chem Commun:1150-1151

36. Zhao Q, Abou-Hamdan H, Désaubry L (2016) Recent Advances in the Synthesis of Flavaglines, a Family of Potent Bioactive Natural Compounds Originating from Traditional Chinese Medicine. European Journal of Organic Chemistry 2016 (36):5908-5916.

doi:10.1002/ejoc.201600437

37. Truitt ML, Conn CS, Shi Z, Pang X, Tokuyasu T, Coady AM, Seo Y, Barna M, Ruggero D (2015) Differential Requirements for eIF4E Dose in Normal Development and Cancer. Cell 162 (1):59-71

38. Yang J, Li B, He QY (2018) Significance of prohibitin domain family in tumorigenesis and its implication in cancer diagnosis and treatment. Cell Death Dis 9 (6):580. doi:10.1038/s41419018-0661-3

39. Polier G, Neumann J, Thuaud F, Ribeiro N, Gelhaus C, Schmidt H, Giaisi M, Kohler R, Muller WW, Proksch P, Leippe M, Janssen O, Desaubry L, Krammer PH, Li-Weber M (2012) The natural anticancer compounds rocaglamides inhibit the Raf-MEK-ERK pathway by targeting prohibitin 1 and 2. Chem Biol 19 (9):1093-1104. doi:10.1016/j.chembiol.2012.07.012 40. Rajalingam K, Wunder C, Brinkmann V, Churin Y, Hekman M, Sievers C, Rapp UR, Rudel T (2005) Prohibitin is required for Ras-induced Raf-MEK-ERK activation and epithelial cell migration. Nature Cell Biology 7 (8):837-843. doi:10.1038/ncb1283 
41. Luan Z, He Y, Alattar M, Chen ZS, He F (2014) Targeting the prohibitin scaffold-CRAF kinase interaction in RAS-ERK-driven pancreatic ductal adenocarcinoma. Mol Cancer 13:11. doi:10.1186/1476-4598-13-38

42. Doudican NA, Orlow SJ (2017) Inhibition of the CRAF/prohibitin interaction reverses CRAF-dependent resistance to vemurafenib. Oncogene 36 (3):423-428.

doi:10.1038/onc.2016.214

43. Yurugi H, Marini F, Weber C, David K, Zhao Q, Binder H, Desaubry L, Rajalingam K (2017) Targeting prohibitins with chemical ligands inhibits KRAS-mediated lung tumours. Oncogene 36 (33):4778-4789. doi:10.1038/onc.2017.93

44. MacArthur IC, Bei Y, Garcia HD, Ortiz MV, Toedling J, Klironomos F, Ralff J, Eggert A, Schulte JH, Kentsis A, Henssen AG (2019) Prohibitin promotes dedifferentiation and is a potential therapeutic target in neuroblastoma. JCI Insight 4 (10):16.

doi:10.1172/jci.insight.127130

45. Doudican NA, Orlow SJ (2016) Inhibition of the CRAF/prohibitin interaction reverses CRAF-dependent resistance to vemurafenib. Oncogene. doi:10.1038/onc.2016.214

46. Yuan G, Chen X, Liu Z, Wei W, Shu Q, Abou-Hamdan H, Jiang L, Li X, Chen R, Desaubry L, Zhou F, Xie D (2018) Flavagline analog FL3 induces cell cycle arrest in urothelial carcinoma cell of the bladder by inhibiting the Akt/PHB interaction to activate the GADD45alpha pathway. J Exp Clin Cancer Res 37 (1):21

47. Ho MY, Liang CM, Liang SM (2015) MIG-7 and phosphorylated prohibitin coordinately regulate lung cancer invasion/metastasis. Oncotarget 6 (1):381-393.

doi:10.18632/oncotarget.2804

48. Yang JW, Murray B, Barbier-Torres L, Liu T, Liu Z, Yang H, Fan W, Wang J, Li Y, Seki E, Mato JM, Lu SC (2019) The mitochondrial chaperone Prohibitin 1 negatively regulates interleukin-8 in human liver cancers. J Biol Chem 294 (6):1984-1996.

doi:10.1074/jbc.RA118.004863

49. Baumann B, Bohnenstengel F, Siegmund D, Wajant H, Weber C, Herr I, Debatin KM, Proksch P, Wirth T (2002) Rocaglamide derivatives are potent inhibitors of NF-kappa B activation in T-cells. J Biol Chem 277 (47):44791-44800. doi:10.1074/jbc.M208003200 50. Li A, Yang L, Geng X, Peng X, Lu T, Deng Y, Dong Y (2015) Rocaglamide-A Potentiates Osteoblast Differentiation by Inhibiting NF-kappaB Signaling. Mol Cells 38 (11):941-949. doi:10.14348/molcells.2015.2353

51. Choi S, Bhagwat AM, Al Mismar R, Goswami N, Ben Hamidane H, Sun L, Graumann J (2018) Proteomic profiling of human cancer pseudopodia for the identification of anti-metastatic drug candidates. Sci Rep 8 (1):5858. doi:10.1038/s41598-018-24256-8

52. Arai MA, Kofuji Y, Tanaka Y, Yanase N, Yamaku K, Fuentes RG, Karmakar UK, Ishibashi M (2016) Synthesis of rocaglamide derivatives and evaluation of their Wnt signal inhibitory activities. Org Biomol Chem 14 (11):3061-3068. doi:10.1039/c5ob02537k

53. Mavila N, Tang Y, Berlind J, Ramani K, Wang J, Mato JM, Lu SC (2018) Prohibitin 1 Acts As a Negative Regulator of Wingless/Integrated-Beta-Catenin Signaling in Murine Liver and Human Liver Cancer Cells. Hepatology Communications 2 (12):1583-1600.

doi:10.1002/hep4.1257

54. Wei Y, Chiang W-C, Sumpter R, Jr., Mishra P, Levine B (2017) Prohibitin 2 Is an Inner Mitochondrial Membrane Mitophagy Receptor. Cell 168 (1-2):224-238.e210

55. Liu S, Wang W, Brown LE, Qiu C, Lajkiewicz N, Zhao T, Zhou J, Porco JA, Jr., Wang TT (2015) A Novel Class of Small Molecule Compounds that Inhibit Hepatitis C Virus Infection by Targeting the Prohibitin-CRaf Pathway. EBioMedicine 2 (11):1600-1606 
56. Zhang W, Liu S, Maiga RI, Pelletier J, Brown LE, Wang TT, Porco JA (2018) Chemical Synthesis Enables Structural Reengineering of Aglaroxin C Leading to Inhibition Bias for HCV Infection. J Am Chem Soc. doi:10.1021/jacs.8b11477

57. Wintachai P, Thuaud F, Basmadjian C, Roytrakul S, Ubol S, Desaubry L, Smith DR (2015) Assessment of flavaglines as potential chikungunya virus entry inhibitors. Microbiol Immunol 59 (3):129-141

58. Too IHK, Bonne I, Tan EL, Chu JJH, Alonso S (2018) Prohibitin plays a critical role in Enterovirus 71 neuropathogenesis. PLoS Pathog 14 (1):e1006778.

doi:10.1371/journal.ppat.1006778

59. Nebigil CG, Desaubry L (2018) Updates in Anthracycline-Mediated Cardiotoxicity. Front Pharmacol 9:1262. doi:10.3389/fphar.2018.01262

60. Bernard Y, Ribeiro N, Thuaud F, Turkeri G, Dirr R, Boulberdaa M, Nebigil CG, Desaubry L (2011) Flavaglines alleviate doxorubicin cardiotoxicity: implication of Hsp27. PLoS One 6 (10):e25302. doi:10.1371/journal.pone.0025302

61. Emhemmed F, Azouaou SA, Hassan S, Lefevbre R, Desaubry L, Muller CD, Fuhrmann G (2019) The synthetic flavagline FL3 spares normal human skin cells from its cytotoxic effect via an activation of Bad. Toxicol In Vitro. doi:10.1016/j.tiv.2019.04.025

62. Ribeiro N, Thuaud F, Bernard Y, Gaiddon C, Cresteil T, Hild A, Hirsch EC, Michel PP, Nebigil CG, Desaubry L (2012) Flavaglines as Potent Anticancer and Cytoprotective Agents. J Med Chem 55 (22):10064-10073. doi:10.1021/jm301201z

63. Fahrig T, Gerlach I, Horvath E (2005) A synthetic derivative of the natural product rocaglaol is a potent inhibitor of cytokine-mediated signaling and shows neuroprotective activity in vitro and in animal models of Parkinson's disease and traumatic brain injury. Mol Pharmacol 67 (5):1544-1555. doi:10.1124/mol.104.008177

64. Becker MS, Breuer R, Krammer PH, Li-Weber M, Schmezer P, Haas SF, Essers MA (2014) The traditional Chinese medical compound Rocaglamide protects nonmalignant primary cells from DNA damage-induced toxicity by inhibition of p53 expression. Cell Death Dis 5:e1000 65. Han J, Zhao Q, Basmadjian C, Desaubry L, Theiss AL (2016) Flavaglines Ameliorate Experimental Colitis and Protect Against Intestinal Epithelial Cell Apoptosis and Mitochondrial Dysfunction. Inflamm Bowel Dis 22 (1):55-67. doi:10.1097/MIB.0000000000000592

66. Kathiria AS, Neumann WL, Rhees J, Hotchkiss E, Cheng Y, Genta RM, Meltzer SJ, Souza RF, Theiss AL (2012) Prohibitin attenuates colitis-associated tumorigenesis in mice by modulating p53 and STAT3 apoptotic responses. Cancer Res 72 (22):5778-5789. doi:10.1158/0008-5472.CAN-12-0603

67. Perez-Perarnau A, Preciado S, Palmeri CM, Moncunill-Massaguer C, Iglesias-Serret D, Gonzalez-Girones DM, Miguel M, Karasawa S, Sakamoto S, Cosialls AM, Rubio-Patino C, Saura-Esteller J, Ramon R, Caja L, Fabregat I, Pons G, Handa H, Albericio F, Gil J, Lavilla R (2014) A trifluorinated thiazoline scaffold leading to pro-apoptotic agents targeting prohibitins. Angew Chem Int Ed Engl 53 (38):10150-10154. doi:10.1002/anie.201405758

68. Cosialls AM, Pomares H, Iglesias-Serret D, Saura-Esteller J, Nunez-Vazquez S, Gonzalez-

Girones DM, de la Banda E, Preciado S, Albericio F, Lavilla R, Pons G, Gonzalez-Barca EM, Gil J (2017) The prohibitin-binding compound fluorizoline induces apoptosis in chronic lymphocytic leukemia cells through the upregulation of NOXA and synergizes with ibrutinib, 5-

aminoimidazole-4-carboxamide riboside or venetoclax. Haematologica 102 (9):1587-1593. doi:10.3324/haematol.2016.162958

69. Moncunill-Massaguer C, Saura-Esteller J, Perez-Perarnau A, Palmeri CM, Nunez-Vazquez S, Cosialls AM, Gonzalez-Girones DM, Pomares H, Korwitz A, Preciado S, Albericio F, Lavilla R, 
Pons G, Langer T, Iglesias-Serret D, Gil J (2015) A novel prohibitin-binding compound induces the mitochondrial apoptotic pathway through NOXA and BIM upregulation. Oncotarget 6 (39):41750-41765. doi:10.18632/oncotarget.6154

70. Pomares H, Palmeri CM, Iglesias-Serret D, Moncunill-Massaguer C, Saura-Esteller J, NunezVazquez S, Gamundi E, Arnan M, Preciado S, Albericio F, Lavilla R, Pons G, Gonzalez-Barca EM, Cosialls AM, Gil J (2016) Targeting prohibitins induces apoptosis in acute myeloid leukemia cells. Oncotarget 7 (40):64987-65000. doi:10.18632/oncotarget.11333

71. Wierz M, Pierson S, Chouha N, Desaubry L, Francois JH, Berchem G, Paggetti J, Moussay E (2018) The prohibitin-binding compound fluorizoline induces apoptosis in chronic lymphocytic leukemia cells ex vivo but fails to prevent leukemia development in a murine model. Haematologica. doi:10.3324/haematol.2017.175349

72. Snyder JR, Hall A, Ni-Komatsu L, Khersonsky SM, Chang YT, Orlow SJ (2005) Dissection of melanogenesis with small molecules identifies prohibitin as a regulator. Chem Biol 12 (4):477484. doi:10.1016/j.chembiol.2005.02.014

73. Djehal A, Krayem M, Najem A, Hammoud H, Cresteil T, Nebigil CG, Wang D, Yu P, Bentouhami E, Ghanem GE, Desaubry L (2018) Targeting prohibitin with small molecules to promote melanogenesis and apoptosis in melanoma cells. Eur J Med Chem 155:880-888. doi:10.1016/j.ejmech.2018.06.052

74. Yun WJ, Kim EY, Park JE, Jo SY, Bang SH, Chang EJ, Chang SE (2016) Microtubuleassociated protein light chain 3 is involved in melanogenesis via regulation of MITF expression in melanocytes. Sci Rep 6:19914. doi:10.1038/srep19914

75. Sato S, Murata A, Orihara T, Shirakawa T, Suenaga K, Kigoshi H, Uesugi M (2011) Marine natural product aurilide activates the OPA1-mediated apoptosis by binding to prohibitin. Chem Biol 18 (1):131-139. doi:10.1016/j.chembiol.2010.10.017

76. Langdahl BL, Andersen JD (2018) Treatment of Osteoporosis: Unmet Needs and Emerging Solutions. J Bone Metab 25 (3):133-140. doi:10.11005/jbm.2018.25.3.133

77. Lee MY, Kim MH, Kim J, Kim SH, Kim BT, Jeong IH, Chang S, Kim SH, Chang SY (2010) Synthesis and SAR of sulfonyl- and phosphoryl amidine compounds as anti-resorptive agents. Bioorg Med Chem Lett 20 (2):541-545. doi:10.1016/j.bmcl.2009.11.104

78. Chang S-Y, Bae SJ, Lee MY, Baek S-h, Chang S, Kim SH Chemical affinity matrix-based identification of prohibitin as a binding protein to anti-resorptive sulfonyl amidine compounds. Bioorg Med Chem Lett 21 (2):727-729. doi:10.1016/j.bmcl.2010.11.123

79. Lee CH, Choi SW, Kim JY, Kim SH, Yoon KH, Oh J, Lee MS (2015) Overexpression of prohibitin-1 inhibits RANKL-induced activation of p38-Elk-1-SRE signaling axis blocking MKK6 activity. Biochem Biophys Res Commun 463 (4):1028-1033.

doi:10.1016/j.bbrc.2015.06.053

80. Kim MH, Park M, Song JS, Park SJ, Kim SH (2011) Anti-resorptive activity and pharmacokinetic study of N(1),N(1)-diisopropyl-N(2)-(diphenylphosphoryl)-2-(4nitrophenyl)acetamidine. Bioorg Med Chem Lett 21 (14):4263-4266.

doi:10.1016/j.bmcl.2011.05.058

81. Kolonin MG, Saha PK, Chan L, Pasqualini R, Arap W (2004) Reversal of obesity by targeted ablation of adipose tissue. Nat Med 10 (6):625-632. doi:10.1038/nm1048

82. Barnhart KF, Christianson DR, Hanley PW, Driessen WH, Bernacky BJ, Baze WB, Wen S, Tian M, Ma J, Kolonin MG, Saha PK, Do KA, Hulvat JF, Gelovani JG, Chan L, Arap W, Pasqualini R (2011) A peptidomimetic targeting white fat causes weight loss and improved insulin resistance in obese monkeys. Sci Transl Med 3 (108):108ra112.

doi:10.1126/scitranslmed.3002621 
83. Sharma A, Qadri A (2004) Vi polysaccharide of Salmonella typhi targets the prohibitin family of molecules in intestinal epithelial cells and suppresses early inflammatory responses.

Proc Natl Acad Sci U S A 101 (50):17492-17497. doi:10.1073/pnas.0407536101

84. Parween F, Yadav J, Qadri A (2019) The Virulence Polysaccharide of Salmonella Typhi

Suppresses Activation of Rho Family GTPases to Limit Inflammatory Responses From Epithelial Cells. Front Cell Infect Microbiol 9:10. doi:10.3389/fcimb.2019.00141

85. Santhanam SK, Dutta D, Parween F, Qadri A (2014) The Virulence Polysaccharide Vi

Released by Salmonella Typhi Targets Membrane Prohibitin to Inhibit T-Cell Activation. Journal of Infectious Diseases 210 (1):79-88. doi:10.1093/infdis/jiu064

86. Garg R, Qadri A (2010) Hemoglobin Transforms Anti-Inflammatory Salmonella typhi

Virulence Polysaccharide into a TLR-2 Agonist. Journal of Immunology 184 (11):5980-5987. doi:10.4049/jimmunol.0903512

87. Parween F, Yadav J, Qadri A (2019) The Virulence Polysaccharide of Salmonella Typhi Suppresses Activation of Rho Family GTPases to Limit Inflammatory Responses From Epithelial Cells. Front Cell Infect Microbiol 9. doi:10.3389/fcimb.2019.00141

88. Jang KS, Baik JE, Kang SS, Jeon JH, Choi S, Yang YH, Kim BG, Yun CH, Han SH (2012)

Identification of staphylococcal lipoteichoic acid-binding proteins in human serum by highresolution LTQ-Orbitrap mass spectrometry. Mol Immunol 50 (3):177-183.

doi:10.1016/j.molimm.2011.11.012

89. You L, Kruse FE, Bacher S, Schmitz ML (2002) Lipoteichoic acid selectively induces the ERK signaling pathway in the cornea. Invest Ophthalmol Vis Sci 43 (7):2272-2277

90. Kuramori C, Azuma M, Kume K, Kaneko Y, Inoue A, Yamaguchi Y, Kabe Y, Hosoya T, Kizaki M, Suematsu M, Handa H (2009) Capsaicin binds to prohibitin 2 and displaces it from the mitochondria to the nucleus. Biochem Biophys Res Commun 379 (2):519-525.

doi:10.1016/j.bbrc.2008.12.103

91. Yoshimaru T, Komatsu M, Tashiro E, Imoto M, Osada H, Miyoshi Y, Honda J, Sasa M, Katagiri T (2014) Xanthohumol suppresses oestrogen-signalling in breast cancer through the inhibition of BIG3-PHB2 interactions. Sci Rep 4:7355. doi:10.1038/srep07355

92. Hati S, Tripathy S, Dutta PK, Agarwal R, Srinivasan R, Singh A, Singh S, Sen S (2016)

Spiro[pyrrolidine-3, 3 -oxindole] as potent anti-breast cancer compounds: Their design, synthesis, biological evaluation and cellular target identification. Sci Rep 6:32213. doi:10.1038/srep32213 93. Elderwish S, Audebrand A, Nebigil CG, Désaubry L (2020) Discovery of 3,3'-pyrrolidinylspirooxindoles as cardioprotectant prohibitin ligands. Eur J Med Chem 186:111859. doi:10.1016/j.ejmech.2019.111859

94. Bettayeb K, Oumata N, Zhang Y, Luo W, Bustos V, Galons H, Greengard P, Meijer L, Flajolet M (2012) Small-molecule inducers of Abeta-42 peptide production share a common mechanism of action. FASEB J 26 (12):5115-5123. doi:10.1096/fj.12-212985

95. Hochard A, Oumata N, Bettayeb K, Gloulou O, Fant X, Durieu E, Buron N, Porceddu M, Borgne-Sanchez A, Galons H, Flajolet M, Meijer L (2013) Aftins Increase Amyloid-beta(42), Lower Amyloid-beta(38), and Do Not Alter Amyloid-beta(40) Extracellular Production in vitro:

Toward a Chemical Model of Alzheimer's Disease? J Alzheimers Dis 35 (1):107-120.

doi:10.3233/jad-121777

96. Guyot A-C, Leuxe C, Disdier C, Oumata N, Costa N, Roux GL, Fernandez-Varela P, Duchon

A, Charbonnier JB, Herault Y, Pavoni S, Galons H, Andriambeloson E, Wagner S, Meijer L, Lund AK, Mabondzo A (2020) A Small Compound Targeting Prohibitin with Potential Interest for Cognitive Deficit Rescue in Aging mice and Tau Pathology Treatment. Scientific Reports 10 (1):1143. doi:10.1038/s41598-020-57560-3 
97. Xun Y, Chen P, Yan H, Yang W, Shi L, Chen G, Du H (2014) Identification of prohibitin as an antigen in Behcet's disease. Biochem Biophys Res Commun 451 (3):389-393.

doi:10.1016/j.bbrc.2014.07.126

98. Jiang L, Dong P, Zhang Z, Li C, Li Y, Liao Y, Li X, Wu Z, Guo S, Mai S, Xie D, Liu Z, Zhou F (2015) Akt phosphorylates Prohibitin 1 to mediate its mitochondrial localization and promote proliferation of bladder cancer cells. Cell Death Dis 6:e1660. doi:10.1038/cddis.2015.40 99. Ande SR, Gu YY, Nyomba BLG, Mishra S (2009) Insulin induced phosphorylation of prohibitin at tyrosine114 recruits Shp1. Biochim Biophys Acta-Mol Cell Res 1793 (8):13721378. doi:10.1016/j.bbamcr.2009.05.008

100. Chowdhury I, Thomas K, Zeleznik A, Thompson WE (2016) Prohibitin regulates the FSH signaling pathway in rat granulosa cell differentiation. Journal of Molecular Endocrinology 56 (4):325-336. doi:10.1530/jme-15-0278

101. Ande SR, Mishra S (2010) Palmitoylation of prohibitin at cysteine 69 facilitates its membrane translocation and interaction with Eps 15 homology domain protein 2 (EHD2). Biochemistry and Cell Biology 88 (3):553-558. doi:10.1139/o09-177 102. Zhu B, Zhai JJ, Zhu HN, Kyprianou N (2010) Prohibitin RegulatesTGF-beta Induced Apoptosis as a Downstream Effector of Smad-Dependent and -independent Signaling. Prostate 70 (1):17-26. doi:10.1002/pros.21033

103. Kettenbach AN, Schweppe DK, Faherty BK, Pechenick D, Pletnev AA, Gerber SA (2011) Quantitative Phosphoproteomics Identifies Substrates and Functional Modules of Aurora and Polo-Like Kinase Activities in Mitotic Cells. Science Signaling 4 (179):15.

doi:10.1126/scisignal.2001497

104. Ande SR, Moulik S, Mishra S (2009) Interaction between O-GlcNAc Modification and Tyrosine Phosphorylation of Prohibitin: Implication for a Novel Binary Switch. PLoS One 4 (2):10. doi:10.1371/journal.pone.0004586

105. Kartha GK, Moshal KS, Sen U, Joshua IG, Tyagi N, Steed MM, Tyagi SC (2008) Renal mitochondrial damage and protein modification in type-2 diabetes. Acta Diabetol 45 (2):75-81. doi:10.1007/s00592-008-0025-z

106. Wang H, Zhou Y, Oyang L, Han Y, Xia L, Lin J, Tang Y, Su M, Tan S, Tian Y, Chen X, Luo X, Liang J, Rao S, Wang Y, Xiong W, Zeng Z, Wang H, Li G, Liao Q (2019) LPLUNC1 stabilises PHB1 by counteracting TRIM21-mediated ubiquitination to inhibit NF-kappaB activity in nasopharyngeal carcinoma. Oncogene. doi:10.1038/s41388-019-0778-6

107. Sileno S, D'Oria V, Stucchi R, Alessio M, Petrini S, Bonetto V, Maechler P, Bertuzzi F, Grasso V, Paolella K, Barbetti F, Massa O (2014) A possible role of transglutaminase 2 in the nucleus of INS-1E and of cells of human pancreatic islets. J Proteomics 96:314-327. doi:10.1016/j.jprot.2013.11.011

108. Battaglia G, Farrace MG, Mastroberardino PG, Viti I, Fimia GM, Van Beeumen J, Devreese B, Melino G, Molinaro G, Busceti CL, Biagioni F, Nicoletti F, Piacentini M (2007) Transglutaminase 2 ablation leads to defective function of mitochondrial respiratory complex I affecting neuronal vulnerability in experimental models of extrapyramidal disorders. $\mathrm{J}$

Neurochem 100 (1):36-49. doi:10.1111/j.1471-4159.2006.04140.x

109. Orru S, Caputo I, D'Amato A, Ruoppolo M, Esposito C (2003) Proteomics identification of acyl-acceptor and acyl-donor substrates for transglutaminase in a human intestinal epithelial cell line. J Biol Chem 278 (34):31766-31773. doi:10.1074/jbc.M305080200

110. Suh SK, Hood BL, Kim BJ, Conrads TP, Veenstra TD, Song BJ (2004) Identification of oxidized mitochondria proteins in alcohol-exposed human hepatoma cells and mouse liver. Proteomics 4 (11):3401-3412. doi:10.1002/pmic.200400971 
111. Kosgodage US, Uysal-Onganer P, MacLatchy A, Kraev I, Chatterton NP, Nicholas AP, Inal JM, Lange S (2019) Peptidylarginine Deiminases Post-Translationally Deiminate Prohibitin and Modulate Extracellular Vesicle Release and MicroRNAs in Glioblastoma Multiforme. Int J Mol Sci 20 (1):23. doi:10.3390/ijms20010103

112. Chander H, Halpern M, Resnick-Silverman L, Manfredi JJ, Germain D (2010) Skp2B attenuates p53 function by inhibiting prohibitin. Embo Reports 11 (3):220-225.

doi:10.1038/embor.2010.2

113. Chander H, Halpern M, Resnick-Silverman L, Manfredi JJ, Germain D (2011) Skp2B

Overexpression Alters a Prohibitin-p53 Axis and the Transcription of PAPP-A, the Protease of Insulin-Like Growth Factor Binding Protein 4. PLoS One 6 (8).

doi:10.1371/journal.pone.0022456

114. Germain D (2011) Skp2 and Skp2B team up against Rb and p53. Cell Division 6. doi:10.1186/1747-1028-6-1

115. Bavelloni A, Piazzi M, Faenza I, Raffini M, D'Angelo A, Cattini L, Cocco L, Blalock WL (2014) Prohibitin 2 represents a novel nuclear AKT substrate during all-trans retinoic acidinduced differentiation of acute promyelocytic leukemia. Faseb J 28 (5):2009-2019.

doi:10.1096/fj.13-244368

116. Sun LG, Cao X, Liu B, Huang HL, Wang X, Sui LY, Yin WM, Ma KW (2011) CaMK IV phosphorylates prohibitin 2 and regulates prohibitin 2-mediated repression of MEF2

transcription. Cellular Signalling 23 (10):1686-1690. doi:10.1016/j.cellsig.2011.06.005

117. Moritz A, Li Y, Guo AL, Villen J, Wang Y, MacNeill J, Kornhauser J, Sprott K, Zhou J,

Possemato A, Ren JM, Hornbeck P, Cantley LC, Gygi SP, Rush J, Comb MJ (2010) Akt-RSK-S6

Kinase Signaling Networks Activated by Oncogenic Receptor Tyrosine Kinases. Science

Signaling 3 (136):11. doi:10.1126/scisignal.2000998

118. Rush J, Moritz A, Lee KA, Guo A, Goss VL, Spek EJ, Zhang H, Zha XM, Polakiewicz RD, Comb MJ (2005) Immunoaffinity profiling of tyrosine phosphorylation in cancer cells. Nature Biotechnology 23 (1):94-101. doi:10.1038/nbt1046

119. Yoshimaru T, Ono M, Bando Y, Chen YA, Mizuguchi K, Shima H, Komatsu M, Imoto I, Izumi K, Honda J, Miyoshi Y, Sasa M, Katagiri T (2017) A-kinase anchoring protein BIG3 coordinates oestrogen signalling in breast cancer cells. Nat Commun 8:12.

doi:10.1038/ncomms 15427 